\title{
Corneal stromal cell responses to traumatic wounds and topical treatments
}

\author{
Marina Kulikovska
}

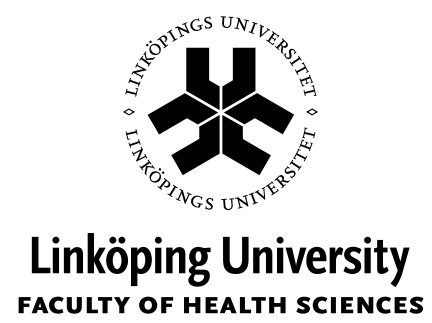

Division of Ophthalmology

Department of Clinical and Experimental Medicine

Linköping University, Sweden

Linköping 2015 
Corneal stromal cell responses to traumatic wounds and topical treatments

CMarina Kulikovska, 2015

Published articles has been reprinted with the permission of the copyright holder.

Printed in Sweden by LiU-Tryck, Linköping, Sweden, 2015

ISBN 978-91-7519-111-9

ISSN 0345-0082 
To my parents with thanks, to my children with hope, and to my husband with love 


\section{Table of Contents}

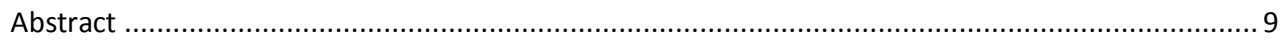

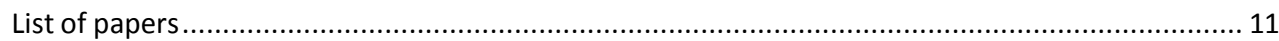

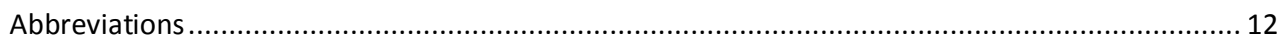

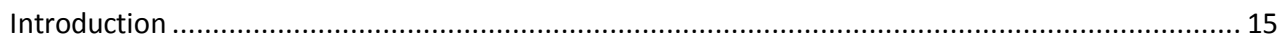

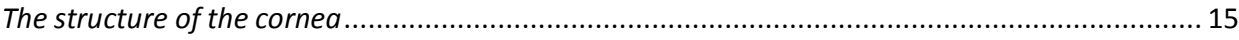



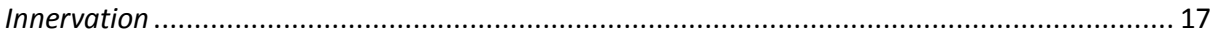



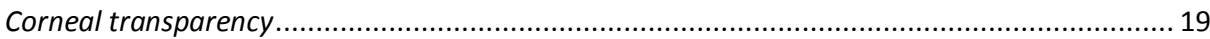

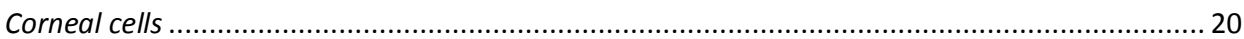

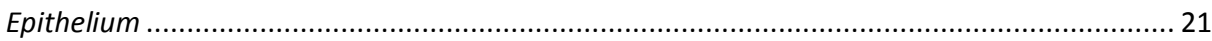

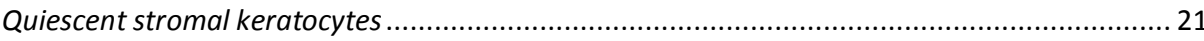

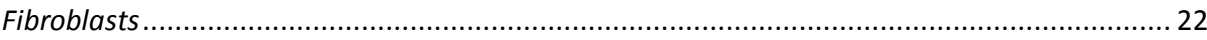

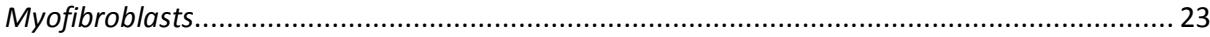

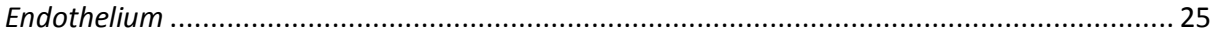

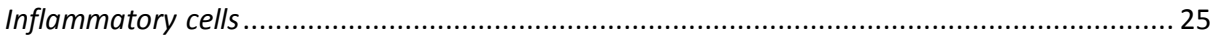



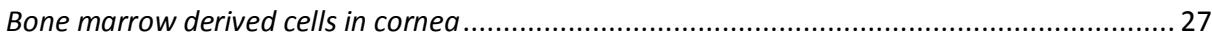

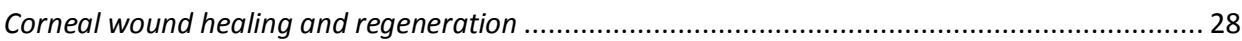

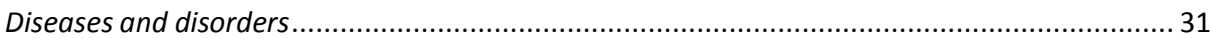

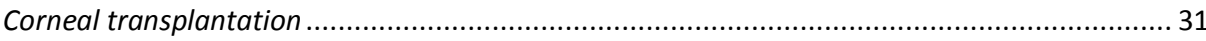





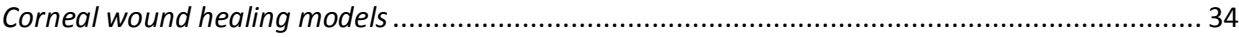

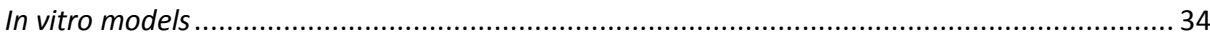



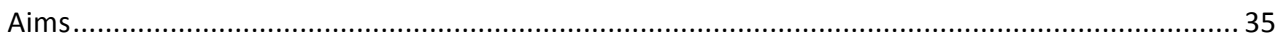

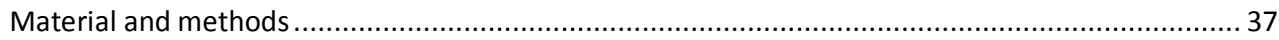

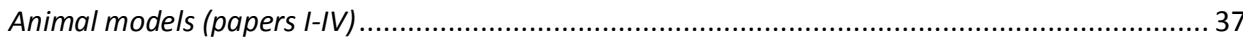

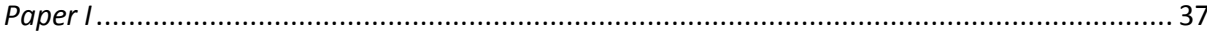




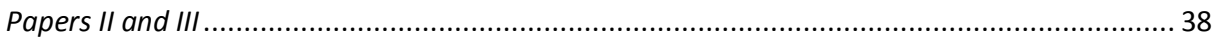



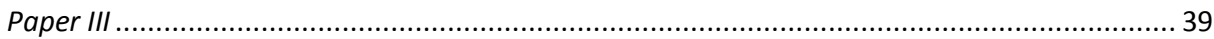





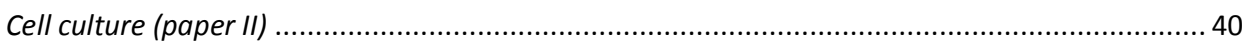

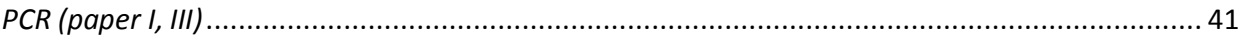

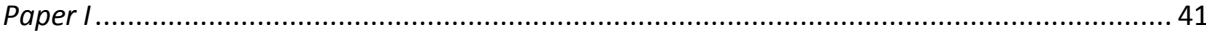



Immunohistochemistry and immunocytochemistry (paper I-IV) ................................................... 42

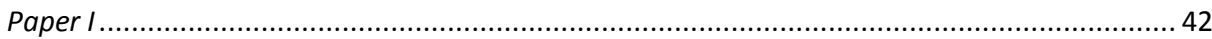

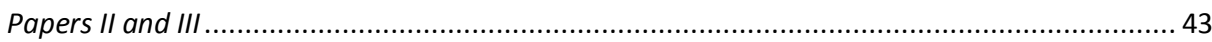

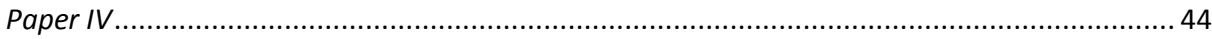



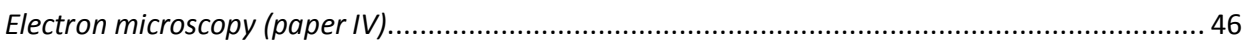

TEM

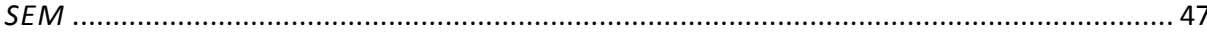



Anterior segment optical coherence tomography (OCT) (paper IV) ......................................... 48

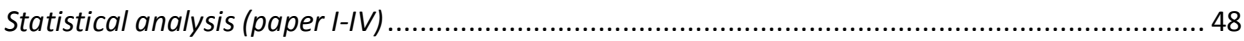

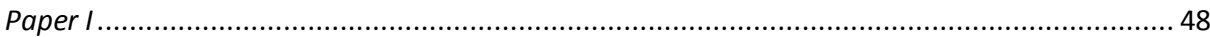

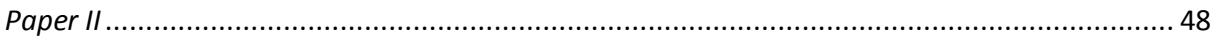

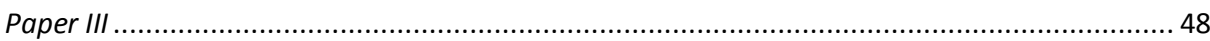



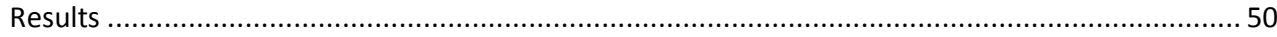

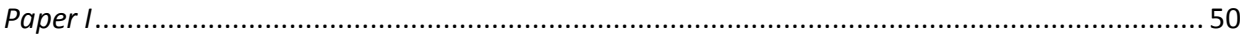



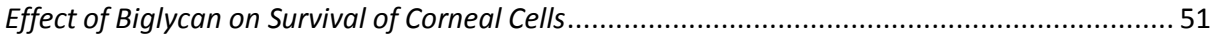

Death of Corneal Stromal Cells in vivo after incisional injury ................................................... 51

$\alpha$-SMA Positive Corneal Stromal Cells in vivo after incisional injury ......................................... 53

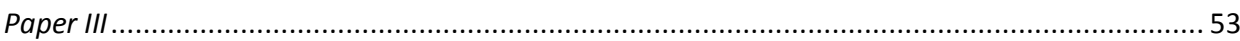

Death of Stromal Keratocytes in injured corneas . the influence of platelet rich plasma $(P R P) \ldots 53$

$\alpha$-SMA Positive Stromal Cells in Healing Corneas after PRP Treatment .................................... 54

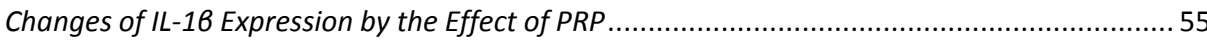


pSMAD2/3 Positive Cells in Healing Corneas after PRP Treatment .......................................... 55

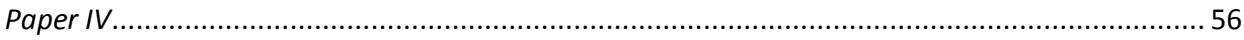

Structural properties of bioengineered porcine constructs (BPCS) .......................................... 56

Femtosecond laser-enabled intrastromal keratoplasty (FLISK) maintains the host cellular environment while BPCs integrate and attract host cells in vivo ............................................ 56

BPCs enable rapid wound healing without inflammation, and initiate stromal regeneration by host myofibroblast recruitment

BPCs contain proteoglycans but no detectable collagen fibril structure or lamellae despite



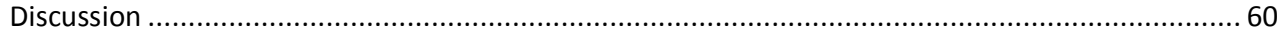

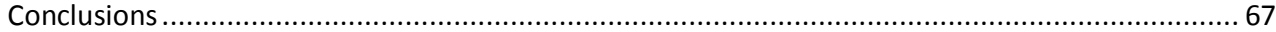

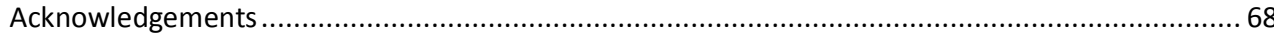

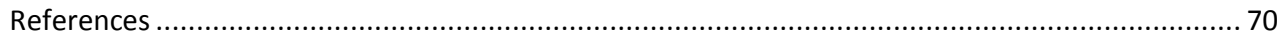

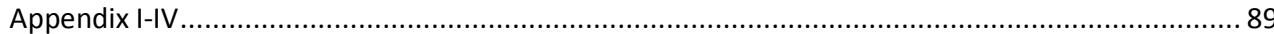




\section{Abstract}

Background. The cornea has unique anatomic, cellular, molecular, and functional features that lead to important mechanistic differences in the process of repair in comparison with what occurs in skin and other organs. The first observable stromal response in corneal wound healing is keratocyte apoptosis. Shortly thereafter, remaining keratocytes in adjacent areas obtain a fibroblastic phenotype and begin to proliferate and to migrate, transforming into myofibroblasts, a phenotype associated with remodeling of stromal collagen. Return to normalcy following wound healing includes elimination of myofibroblasts and restoration of the quiescent state of the keratocytes. Often, however, a wound healing response results in the persistence of myofibroblasts and their subsequent production of fibrous scar tissue.

Aims. The overall aim is to understand the role of keratocytes, and their phenotypic variations in a cornea subjected to various types of trauma or treatments. More specific aims are to define expression pattern of alpha-smooth muscle actin ( $\alpha-S M A)$ and chaperonin containing T-complex polypeptide 1 (CCT) in ultraviolet radiation wound model, to evaluate the effect of biglycan and platelet rich plasma (PRP) treatment during wound healing after corneal incision, and to characterize the structure of the bioengineered porcine construct and its interaction with stromal cells after implantation.

Methods. CCT and $\alpha$-SMA expression level was evaluated by reverse transcription polymerase chain reaction (RT-PCR) in rabbit corneas subjected to ultraviolet radiation (UVR). Effect of biglycan and PRP on keratocyte phenotype and survival was evaluated by immunohistochemistry, and real time PCR using rat corneas after 
incisional wounding. Bioengineered porcine construct (BPC) was implanted into rabbit corneas using femtosecond laser-enabled intrastromal keratoplasty (FLISK) and characterized by means of immunohistochemistry, electron microscopy, and in vivo confocal microscopy (IVCM).

Results and conclusions. In a mild wound, the expression of a-SMA mRNA is followed by expression of mRNA of at least one subunit of the complex folding $\alpha$ SMA. At protein level, $\alpha$-SMA is detected in the front line of repopulating keratocytes. Expression levels for both mRNAs decline as the stroma repopulation process progresses.

Biglycan appears to accelerate corneal wound healing in vivo by modulating myofibroblast apoptosis, resulting in removal of myofibroblasts that may otherwise compromise corneal transparency.

PRP treatment resulted in suppressed stromal cell apoptosis followed by SMAD3 activation and a greater proportion of myofibroblasts present at the wound site. Suppression of stromal cell apoptosis after corneal wounding by use of a growth factor rich formulation may lead to myofibroblast accumulation by modulation of the TGF- $\beta$ pathway.

A cost-effective BPC extracellular matrix equivalent can incorporate cells passively to initiate normal regenerative healing of the corneal stroma.

Taken together, results present an interesting possibility to combine BPC implantation and topical biglycan treatment to improve surgical outcome in future studies. 


\section{List of papers}

This thesis is based on the following papers, which will be refered to in the text by their Roman numerals.

I. Koulikovska M, Podskochy A, Fagerholm P. The expression pattern of the subunit of chaperonin containing T-complex polypeptide 1 and its substrate, alpha-smooth muscle actin, during corneal wound healing. Acta Ophthalmol Scand 2005; 83(5):543-548.

II. Koulikovska M, Szymanowsky O, Lagali N, Fagerholm P. Platelet rich plasma prolongs myofibroblast accumulation in corneal stroma with incisional wound. Curr Eye Res Accepted for publishing.

III. Koulikovska M, Szymanowsky O, Lagali N, Fagerholm P. Topical biglycan modulates stromal cell apoptosis in corneal incisional wound model. Submitted manuscript.

IV. Koulikovska M, Rafat M, Petrovski G, Vereb Z, Akhtar S, Fagerholm P, Lagali $\mathrm{N}$. Enhanced regeneration of corneal tissue via a bioengineered collagen construct implanted by a non-disruptive surgical technique. Tissue Eng Part A 2014 Nov 20. [Epub ahead of print]. 


\section{Abbreviations}

ABCG2 ATP-binding cassette sub-family G member 2

AEC 3-amino-9-ethylcarbazole

ALDH aldehyde dehydrogenase

ANOVA analysis of variance

ATP adenosine triphosphate

BPC bioengineered porcine construct

BrdU bromodeoxyuridine

CCT chaperonin containing T-complex polypeptide 1

cDNA complementary deoxyribonucleic acid

CTGF connective tissue growth factor

DAB 3, 3'-diaminobenzidine

DMEM Dulbecco's minimum essential medium

DNAse deoxyribonuclease

EDC 1-ethyl-3-(3-dimethylaminopropyl) carbodiimide

ECM extracellular matrix 


\begin{tabular}{|c|c|}
\hline ELISA & enzyme-linked immunosorbent assay \\
\hline FGF & fibroblast growth factor \\
\hline FLISK & femtocesond laser-enabled intrastromal keratoplasty \\
\hline GAPDH & glyceraldehyde 3-phosphate dehydrogenase \\
\hline GFP & green fluorescent protein \\
\hline HCECS & human corneal endothelial cells \\
\hline $\mathrm{H} \& \mathrm{E}$ & hematoxylin and eosin \\
\hline HRP & horseradish peroxidase \\
\hline IGF-II & insulin-like growth factor-II \\
\hline IL & interleukin \\
\hline IL-1 RA & interleukin-1 receptor antagonist \\
\hline IVCM & in vivo confocal microscopy \\
\hline LASIK & laser in situ keratomileusis \\
\hline $\mathrm{MHC}$ & major histocompatibility complex \\
\hline MMP & matrix metalloproteinase \\
\hline NHS & $\mathrm{N}$-hydroxysuccinimide \\
\hline OCT & optical coherence tomography \\
\hline
\end{tabular}


PBS phosphate buffered saline

PCNA proliferating cell nuclear antigen

PDGF platelet-derived growth factor

PRGF plasma rich in growth factors

PRK photorefractive keratectomy

PRP platelet rich plasma

PTK phototherapeutic keratectomy

RNA ribonucleic acid

RT-PCR reverse transcriptase polymerase chain reaction

SEM scanning electron microscopy

a-SMA $\quad \alpha$-smooth muscle actin

TEM transmission electron microscopy

TGF $\beta \quad$ transforming growth factor $\beta$

TKT transketolase

TNF- $\alpha \quad$ tumor necrosis factor $\alpha$

UVR ultraviolet radiation 


\section{Introduction}

The structure of the cornea

The cornea is the eye's outermost tissue. Beside an obvious protective function, this tissue serves as a lens and ultraviolet filter. For the refractive function of the cornea, its most important properties are its transparency, dome shape and absence of blood vessels. The highly organized layers comprised of different cell types and extracellular matrix molecules along with proper innervation help maintain corneal transparency and to effectively serve its refractive and physiologic functions.

\section{Layers}

The human cornea has five basic layers, each serving an important function. From anterior to posterior, the layers of the human cornea are:

- epithelium

- Bowman's layer

- stroma

- Descemet's membrane

- endothelium.

The human corneal epithelium has five to seven cell layers and an accepted central thickness of approximately 49 to $52 \mu \mathrm{m}$ (Li 2012). The cells of the outermost layer are 2-3 layers of superficial squamous cells, with flattened nuclei. Then follow two or three layers of polyhedral cells, commonly known as wing cells. Lastly, there are columnar cells, known as basal. The corneal epithelium is a highly active, self- 
renewing layer; a complete turnover of central cells in vertical direction occurs in approximately 5 to 7 days (Hanna 1960). The irregularity of the epithelial cell surface is compensated by the tear-film creating a smooth refractive interface, at the most significant component of the total refractive power of the eye.

Bowman's layer is a smooth, acellular, nonregenerating layer, located between the basal epithelium and the stroma. It is composed of strong, randomly oriented collagen fibrils in which the smooth anterior surface faces the epithelial basement membrane and the posterior surface merges with the collagen lamellae of the corneal stroma. The function of the Bowman's layer remains unclear and appears to have no critical function in corneal physiology (Wilson 2000). Recently, it was postulated that the layer may act as a physical barrier to protect the subepithelial nerve plexus and thereby hasten epithelial innervation and sensory recovery after injury (Lagali 2009a). Moreover, it may also serve as a barrier that prevents direct traumatic contact with the corneal stroma and hence it presence or absence influences stromal wound healing and the associated restoration of anterior corneal transparency at the morphological level (Lagali 2009a). In adult humans, Bowman's layer is $10.7 \pm 1.6 \mu \mathrm{m}$ thick as measured by IVCM (Germundsson 2013). This layer is well developed in higher mammals and is absent or very thin in nonprimates. (Hayashi 2002).

The corneal stroma is fibrous, tough, and highly transparent, and about $500 \mu \mathrm{m}$ thick in humans. It is composed of about 200 lamellae consisting of mainly type I collagen fibrils (Oyster 1999). The fibrils within each lamella are parallel with one another, but are at right angles to each other in adjacent lamellae. About $10 \%$ of the stroma is occupied by sparsely distributed interconnected keratocytes. There is also a population of bone marrow-derived cells and so-called stromal stem cells. The 
corneal stroma constitutes the bulk of the cornea and the high transparency is essential for the normal transmission and refraction of light.

Descemet's membrane is the basement membrane that lies between the corneal stroma and the endothelial layer. It is composed of a collagens secreted by the single layer of squamous epithelial cells that compose the endothelial layer of the cornea. Its thickness ranges from $3 \mu \mathrm{m}$ at birth to 8-10 $\mu \mathrm{m}$ in adults (Johnson 1982).

The corneal endothelium is a single layer, approximately $5 \mu \mathrm{m}$ thick, of specialized, flattened, mitochondria-rich cells that line the posterior surface of the cornea and face the anterior chamber of the eye. The corneal endothelium governs fluid and solute transport across the posterior surface of the cornea and actively maintains the cornea in a state of optimal hydration that is required for optical transparency (Goldman 2012). Unlike the corneal epithelium, corneal endothelial cells are postmitotic and are not believed to divide in the post-natal human cornea. Endothelial cell loss, if sufficiently severe, can cause endothelial cell density to fall below the threshold level needed to maintain a proper corneal state of hydration, thus impairing corneal transparency.

\section{Innervation}

The cornea is the most densely innervated tissue in the human body. Although the entire sensory innervation of the cornea is derived from a relatively small number of neurons, each neuron supports as many as 200-3000 individual corneal nerve endings (Spadea 2013).

Most of the corneal nerves are derived from the ophthalmic division of the trigeminal nerve, via the anterior ciliary nerves and to a lesser degree from the maxillary nerve. The limbus and the peripheral cornea also receive autonomic sympathetic 
innervation from the superior cervical ganglion (Marfurt 2001). Prior to entering the cornea, the nerve bundles traverse the limbus and contribute fibers to the limbal, or pericorneal plexus, a dense, ring-like meshwork of nerve fibers that completely surrounds the peripheral cornea (Marfurt 2010). Nerves enter the cornea in the middle third of the stroma and run forward anteriorly in a radial fashion towards the centre. They lose their myelin sheath approximately one millimeter from the corneal limbus in order to maintain the transparency of the cornea (Marfurt 2010), giving rise through repetitive branching to varying numbers of progressively smaller stromal nerves that anastomosed frequently, often at highly acute branch points, to form a moderately dense midstromal plexus. In the interface between Bowman's layer and the anterior stroma, the stromal nerves form the subepithelial nerve plexus; hence, they bend horizontally and vertically and perforate Bowman's layer to form the subbasal nerve plexus, providing innervation to the basal epithelial cell layer to finally terminate within the superficial epithelial layers (Guthoff 2005).

Primary afferent neurons innervating the cornea are able to sense if the ocular surface is exposed to damaging or potentially damaging stimuli and evoke protective autonomic and somatic reflexes, including lacrimation and blinking, as well as irritating and painful sensations (Belmonte 2004; Evinger 2002; Pellegrini 1995). Corneal innervation not only provides sensation but is also integral to the maintenance of the structure and function of the cornea to regulate epithelial integrity, proliferation and wound healing in relation to disease, trauma or surgery (Müller 2003; Gallar 2004).

Corneal nerves are capable of regeneration; however, it is a slow, imperfect process and the regeneration that takes place after most corneal surgeries is characterized by reduced nerve density, alterations in nerve architecture, and diminished corneal 
sensitivity. Furthermore, denervation of the cornea can lead to corneal degeneration indicated by stromal thinning and disruption of the corneal epithelium (Ferrari 2011, 2013; Ueno 2012).

\section{Refractive nature}

The cornea is the most powerful refracting surface of the optical system of the eye, accounting for two-thirds of the eye's refractive power. The refractive power of the cornea depends on its curvature and the difference in refractive indexes between it and air (Waltman 1987). The index of refraction of the cornea is about 1.376. Rays pass from the cornea into the aqueous humor which has an index of refraction of about 1.336, so the greatest change in refractive index occurs between air (1.00) and the tear film (1.34).

\section{Corneal transparency}

For optimal vision, the cornea must efficiently transmit incident light by maintaining its transparency. The cornea is kept transparent by anatomic/physical as well as physiological factors and the corneal epithelium, stroma, and endothelium are involved in transparency maintenance.

The tight nonkeratinized epithelium, in combination with the transporting endothelium, work to maintain the cornea in a state of relative dehydration. Corneal epithelium to a large extent is impermeable to water, and endothelial layer is capable of pumping fluid out of the cornea with high effectiveness (Maurice 1972). The ultrastructural basis for this impermeability comes from the tight junctions known as zonula occludens that seal the intercellular space between the superficial epithelial cells. Malfunction of the endothelium and/or epithelium may cause stromal edema. Proteoglycans, by interacting with collagen fibrils, determine both the 
architecture of the corneal matrix and its water-retaining properties (Borcherding 1975). Evidence from the lumican knockout mouse experiments (Chakravarti 2000) suggests that rather than the specific arrangement of collagen fibrils, it is the interfibrillar spacing and proteoglycan content that plays an important role in ensuring corneal transparency. A further structural adaptation to minimize light scatter is thought to be the expression of corneal crystallins in keratocytes (Jester 2005). In vivo confocal microscopy reveals that while light scattering is (as expected) maximal at the anterior superficial epithelial and posterior endothelial surfaces, light scattering within the stroma is restricted to keratocyte nuclei which are relatively scarce (Jester 2008).

Corneal avascularity is an essential element of corneal transparency. The natural balance of local pro- and anti-angiogenic factors maintains corneal avascularity (Azar 2006; Kaminska 1993). Other factors contributing to corneal transparency are the absence of a myelin sheath on central corneal axons (although scarce nerves in perilimbal area retain myelin), the absence of pigment, and normal precorneal tear film. Dysfunction in any of these components can cause a loss of transparency and loss of function.

\section{Corneal cells}

The three major corneal layers comprise different cell types. Corneal epithelium consists of non-keratinized stratified squamous epithelial cells. The epithelial stem cells are thought to reside at the corneal limbus. Stroma is resided by quiescent corneal keratocytes which become activated in stress conditions. These activated cells are designated in different sources either as "active keratocytes" or "fibroblasts" or are said to assume a "repair phenotype". After extensive injuries or at the 
advanced stages of healing process a number of keratocytes transform into myofibroblasts. A small number of immune cells such as Langerhans cells, stromal dendritic cells, and macrophages are present in the cornea. Stem cells derived from bone marrow can be found in the corneal stroma (Wilson 2012). Finally, endothelial cells cover the corneal inner surface. Stem cells for the keratocytes or for the endothelium have not been identified.

\section{Epithelium}

The corneal epithelium consists of several layers of cells. The cells of the deepest layer are columnar, known as basal cells composing a single-cell layer approximately $20 \mu \mathrm{m}$ tall. They are characterized by lateral intercellular gap junctions and an extensive basal hemidesmosomal system. Besides the stem cells and transient amplifying cells, basal cells are the only corneal epithelial cells regularly undergoing mitosis (Wiley 1991). They are the source of another two types of corneal epithelial cells, wing and superficial cells. Suprabasal or wing cells are polyhedral cells which possess tight lateral intercellular junctions. Lastly, squamous cells are flat, polygonal cells with flattened nuclei, joined laterally by tightjunctional complexes.

\section{Quiescent stromal keratocytes}

Corneal keratocytes are specialized fibroblastic cells residing in the stroma.

Keratocytes developmentally originate from neural crest cells and then differentiate into mesenchymal cells (Hayashi 1986). By the moment of eye opening the proliferation of keratocytes is finished and most of them are in the quiescent state (West-Mays 2006). Keratocytes form an interconnected network, with dendrites of neighboring cells contacting each other (Müller 1995). By using confocal microscopy 
in vivo, average full-thickness central keratocyte density in the human stroma was estimated at $20522 \mathrm{cell} / \mathrm{mm}^{3}$, with the highest density in the anterior $10 \%$ of the stroma. The density was correlated with age, decreasing $0.45 \%$ per year (Patel 2001).

Widely accepted phenotypic markers for quiescent keratocytes are so-called crystallins, and the keratan sulfate proteoglycan keratocan. Different sets of crystallins are typical to distinct species (Jester 2008). Crystallins expressed by human keratocytes are aldehyde dehydrogenases ALDH1A1 (Jester 2005), ALDH3A1 (Lassen 2006), ALDH2 (Pei 2006) and transketolase (TKT) (Jester 2005). Normal crystallin content reduce backscatter of light from the keratocytes by leveling the refracting index with the surrounding matrix and thereby maintaining transparency (Jester 2008). The crystallins also play role in defense mechanisms against oxidative stress (Lassen 2008). In its turn, keratan sulfate produced by keratocytes appears to be related to maintenance of a level of tissue hydration critical for corneal transparency (Funderburgh 2000; Funderburgh 2001).

\section{Fibroblasts}

Upon injury to the cornea, a subpopulation of keratocytes become active, proliferate and start synthesizing matrix metalloproteinases that cause tissue remodeling. These activated cells are designated either as active keratocytes" or "fibroblasts" or are said to assume a "repair phenotype".

Fibroblasts proliferate and move about the wounded area, where they secrete collagenases, proteases, and extracellular matrix components, all of which are used in reconstructing the damaged stroma (Girard 1993). 
Keratocyte transition to the activated state with their subsequent proliferation and migration, is stimulated by the orchestrated release of different cytokines and growth factors from neighboring cells. Transforming growth factor (TGF) is released by transient population of macrophages and other inflammatory cells, such as neutrophils and lymphocytes (along with platelet-derived growth factor PDGF) and also by epithelium. TGF in its turn cause release of fibroblast growth factor (FGF) and connective tissue growth factor (CTGF) by keratocytes. Epithelial cells, besides of TGF, release FGF and interleukin-1 (IL-1) which cause an autocrine loop in keratocytes. In addition, insulin-like growth factor II (IGF-II) from stroma and FGF, TGF and PDGF from tear fluid take part in the wound healing response by inducing activation of keratocytes. (Wilson 2001a; Fini 1999).

Activated keratocytes or fibroblasts enter into the cell cycle and migrate to the site of injury. Their morphological characteristics include cell size and organelle content increase, fusiform shape, multiple nucleoli, and lack of cytoplasmic granules. Markers for this phenotype are fibronectin and collagenase expression and loss of keratocyte gene marker expression, namely TKT and ALDH1A1. (Jester 1994; Girard 1993).

\section{Myofibroblasts}

After more severe injuries or at the advanced stages of healing process a number of keratocytes can become myofibroblasts, another repair phenotype which is not detectable in normal unwounded corneas (Ishizaki 1993; Chaurasia 2009). TGF $\beta$ modulates the generation of myofibroblasts from either corneal fibroblast or bone marrow-derived cell precursors and interaction between the two cell types could be important in the generation of myofibroblasts (Singh 2012). 
Myofibroblasts are fibroblastic cells that have ultrastructural and physiological characteristics of smooth muscle cells, such as prominent intracellular microfilament bundles (stress fibers) and contractile responses to smooth muscle agonists (Luttrull 1985; Jester 1999a; Jester 1995). a-SMA is the most common marker used to detect myofibroblasts. Although, in addition to aSMA, mature myofibroblasts also express vimentin and desmin as well as $\alpha_{5} \beta_{1}$ and/or $\alpha_{v} \beta_{3}$ integrins that localize to focal adhesions involved in the assembly of fibronectin fibrils (Chaurasia 2009; Jester 1999). These molecules are a part of a cellular apparatus that allows myofibroblasts to exert mechanical force and participate in wound matrix organization and wound contraction (Jester 1995).

Myofibroblasts produce high levels of type I collagen, fibronectin, hyaluronan, and also have altered proteoglycan expression compared to keratocytes; they express biglycan but only low levels of keratan sulfate proteoglycans (Karamichos 2010; Funderburgh 2001). This excretion may serve a tissue regenerative function, but also contributes to stromal opacity in the transparent cornea, in addition to the decreased transparency of the myofibroblasts themselves that is attributable to diminished crystallin protein production compared to keratocytes (Jester 1999b, Cintron 1977; Cintron 1978; Hassell 1983; Maguen 1997; Funderburgh 1998; Ljubimov 1998; Sundarraj 1998).

Transparency can be restored to the disorganized and opaque extracellular matrix (ECM) produced by myofibroblasts by turnover and the production of an organized ECM (Cintron 1978; Hassell 1983). In this case, the myofibroblasts would have to become (or be replaced by) wound fibroblasts. 


\section{Endothelium}

Corneal endothelial cells form a monolayer of specialized hexagonal, flattened, mitochondria-rich cells, attached to the rest of the cornea through Descemet's membrane, an acellular layer composed mostly of collagenous waste products of endothelial cells.

Corneal endothelial cells (CECs) are believed to arise from the neural crest (Johnston 1979; Bahn 1984). The adult corneal endothelial cell density achieves approximately $2400-3200$ cells/mm². Human CECs (HCECs) normally display limited proliferative capacity in vivo (Egan 1998; Senoo 2000), because they are arrested in a G1 phase (Joyce 1996a, Joyce 1996b). Therefore, the number of HCECs gradually decreases with age (Murphy 1984; Bourne 1997; Hollingsworth 2001) and declines dramatically after endothelial damage due to trauma, phacoemulsification, corneal transplantation, or acute angle-closure glaucoma.

The principal physiological function of the corneal endothelium is to regulate the hydration state through an active ATP and biocarbonate-dependent pump and therefore maintain transparency of the cornea (Krachmer 2005).

Since the cornea is avascular, it is also an important system for the passage of nutrients and waste removal through simple diffusion, facilitated diffusion, and active transport mechanisms (Bonanno 2003).

\section{Inflammatory cells}

Wound healing is normally accompanied by inflammation that is triggered by the inciting injury (Sotozono 1997).

The corneal tissue is not vascularized, and does not contain lymphoid cells or other defense mechanisms, apart from some dendritic cells (Hamrah 2003). Therefore, 
many immune responses within the cornea, come from surrounding vascularized tissues but there are innate immune responsive cells that reside within the cornea.

Upon injury, epithelial cells and keratocytes start to secrete pro-inflammatory cytokines. Interleukin-1a is stored in epithelial cells and automatically released when the cell membrane is ruptured by infection or trauma. This cytokine stimulates leukocyte infiltration (Stapleton 2008). To a lesser extent than IL-1, injury to the epithelium increases expression of tumor necrosis factor alpha (TNF- $\alpha$ ) that similarly recruits leukocytes (Sotozono 1997; Saika 2007; Wilson 2001a). The cornea has also been found to secrete an IL-1 $\alpha$ antagonist (IL-1RA), which decreases leukocyte invasion of the cornea and suppresses neovascularization (Moore 2002).

Keratocytes also can be influenced by IL-1 $\alpha$ and TNF $\alpha$ to produce IL-6. IL-6 is found to combine synergistically with other interleukins to increase co-stimulation of other immune aspects as well as increase antibody secretion. Furthermore, keratocytes have also been found to secrete IL-8, which attracts neutrophils, in infections involving the herpes simplex virus (Oakes 1993).

\section{Corneal limbal epithelial stem cells}

The stem cells are thought to reside at the corneal limbus. It has been suggested that corneal stem cells can be present throughout the entire corneal surface and give rise to new cells for the purpose of maintaining ocular homeostasis. The limbus acts as the potential stem cell source for corneal wound healing (Majo 2008). The stem cells are maintained by a variety of factors which include microenvironment, growth factors and cytokines. During homeostasis and following injury to the corneal epithelium, the limbal stem cells divide to produce daughter transient amplifying cells that proliferate, migrate, and differentiate to replace lost cells. The rate of 
proliferation and differentiation of stem cells is modulated by many intrinsic and extrinsic factors.

Stem cell markers that have been proposed for ocular tissue include $\Delta N p 63 \alpha$, ABCG2, integrin a9 and Bmi-2 (Di lorio 2005; Wang 2005), however, definite stem cell identification remains elusive.

\section{Bone marrow derived cells in cornea}

The self-renewal capacity of stromal keratocytes is less well recognized, and, consequently, the search for stem cells at these sites has not been pursued to any great extent. The mechanisms for tissue and cell maintenance and renewal during adult life are considered to depend on pluripotent stem cells. It was suggested that bone marrow cells have the potential to form new tissue cells especially after injury either transdifferentiating into a fully mature tissue-specific cell or more likely fusing with existing cells to form a multinucleated cell (Alvarez-Dolado 2003). Some researchers have suggested that in corneal stroma there are stem cells derived from bone marrow which are CD34 positive (Toti 2002; Joseph 2003).

Chinnery et al. (Chinnery 2008) found that mice injected by bone marrow cells from GFP expressing mice, exhibited a resident population of bone marrow cells in the cornea. Further research has shown that the normal mouse cornea contains two populations of bone marrow-derived leukocytes, both of which are distinct from stromal keratocytes. The larger population resembles CD34+ hematopoietic stem cells, whereas the smaller population are CD34- CD11b+ MHC class II+ macrophages. A very small percentage comprises plasmacytoid dendritic cells (Sosnová 2005). 
To date there is no evidence that either transdifferentiating or fusing of bone marrow derived cells with keratocytes occurs in the eye, and for the moment the most apparent role for corneal hemapoetic stem cells seems to be to replenish tissue resident macrophages and dendritic cells.

Thus, the function of bone marrow derived stem cells in cornea and the relationship between bone marrow derived cells and keratocytes remains unknown.

\section{Corneal wound healing and regeneration}

The cornea has unique anatomic, cellular, molecular, and functional features that lead to important mechanistic differences in the process of repair in comparison with what occurs in skin and other organs. (Fini 2005). Corneal stromal wound healing involves a series of complex matrix-cell interactions that include inflammation, cellular migration and proliferation of keratocytes, new collagen synthesis, and, lastly, tissue remodelling (Fig. 1).

The first observable stromal response in corneal wound healing is keratocyte apoptosis. Shortly thereafter, remaining keratocytes in adjacent areas obtain a fibroblastic phenotype and begin to proliferate and to migrate, transforming into myofibroblasts, a phenotype associated with remodeling of stromal collagen. Return to normalcy following wound healing includes elimination of myofibroblasts and restoration of the quiescent state of the keratocytes. Often, however, a wound healing response results in the persistence of myofibroblasts and their subsequent production of fibrous scar tissue. In the cornea, this scar tissue can cause opacities in the visual axis and thereby impair vision (reviewed in Wilson 2001b). The myofibroblasts are responsible for more severe and permanent scarring. Therefore, 
the transformation of keratocytes into myofibroblasts is a key event in the healing processes.

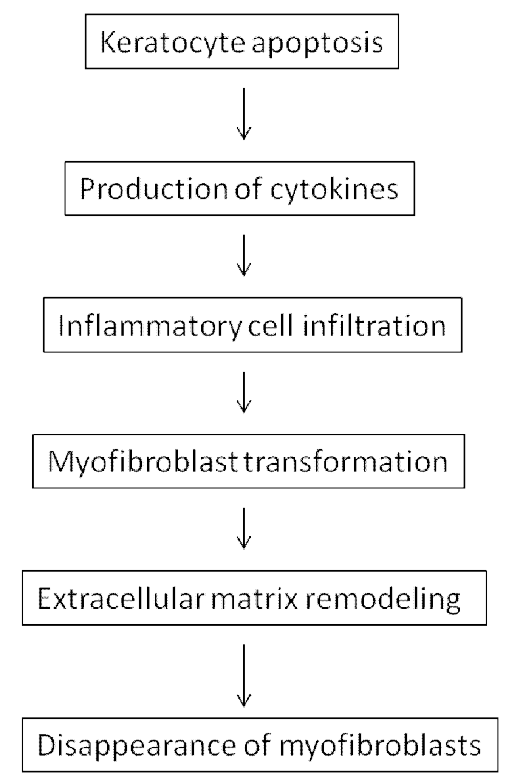

Figure 1. The important aspects of the wound healing cascade in the cornea. (Adapted from Arch Ophthalmol. 2001;119(6):889-896)

TGF- $\beta$ is of prime importance. It induces the transformation of keratocytes or corneal fibroblasts derived from keratocytes into myofibroblasts. Myofibroblasts restore the integrity of the cornea by contracting the wound, secreting extracellular matrix, and generating adhesion structures with the surrounding substrate. The signaling pathway for TGF- $\beta$ family members is the SMAD pathway. SMADs are transcription factors that transduce extracellular TGF- $\beta$ ligand signaling from cell membrane bound TGF- $\beta$ receptors into the nucleus where they activate transcription of TGF- $\beta$ target genes. SMAD2 and SMAD3 are directly phosphorylated and activated upon TGF- $\beta$ ligand signaling. 
The stromal injury response is stimulated by the release of certain cytokines and begins with epithelial compromise leading to swelling of the stroma, apoptosis of keratocytes and invasion of inflammatory cells. This may occur even without penetration to the stroma (Wilson 1998; Robb 1962). Early on, leukocytes are recruited to the site of injury where they serve to protect against infection but can also contribute to tissue damage (Robb 1962; Kenyon 1985). There is also evidence that the corneal epithelial healing rate is delayed in the absence of leukocytes in vivo, and proliferative cell nuclear antigen (PCNA) expression increases in the presence of leukocytes (Gan 1999). The keratocytes nearest the wound undergo apoptosis and those adjacent to this area are activated to become fibroblasts or myofibroblasts with resulting expansion of the fibroblast population by mitosis (Wilson 1996; Fini 1999).

These transformed cells then migrate to the wound and produce collagens, glycoproteins and proteoglycans which form the new stromal extracellular matrix to fill the defect (Malecaze 1997; Desmouliere 2005). In this early phase, the newly synthesized collagen fibrils are usually larger in diameter than normal, due to the higher concentration of chondroitin/dermatan sulphate. This material may contract and opacify which reduces corneal transparency and may cause permanent scarring.

The number of transformed keratocytes start to decline once the wound is filled and a slow remodelling phase takes place. This phase is thought to be controlled by various matrix metalloproteinases (MMPs), to reorganise the collagen to restore transparency (Fini 1999). Depending on the balance of mediators, MMPs and the extent of the wound, the outcome of stromal healing can be regeneration of normal stromal structure, an opaque scar, stromal melting or neovascularization (Matsubara 
1991; Strissel 1997; Gabison 2009). The formation of a stromal scar in humans is therefore a dynamic process and clinical changes can be noted by slit-lamp biomicroscopy for several years post wounding.

\section{Diseases and disorders}

A special type of healing is keloid formation. Corneal keloids are hypertrophic scars of the cornea that may be present at birth following intra-uterine trauma, but more often they appear spontaneously or after minor trauma or cornea disease throughout life. The opacity appears to be an inappropriate repair response of the corneal tissue to trauma. The stromal nodules are composed of scarce proliferating myofibroblasts, activated fibroblasts, and haphazardly arranged fascicles of collagen. Immunohistochemical stains show spindle cells that express immunoreactivity for vimentin and alpha smooth muscle actin (Holbach 1990). Keloids stain positive with Congo Red as they contain amyloid proteins.

\section{Corneal transplantation}

Corneal transplantation is a surgical procedure where a damaged or diseased part of the cornea is replaced in its entire thickness (penetrating keratoplasty) or in part (either anterior or posterior lamellar keratoplasty), with donor tissue.

Transplantation is performed when other therapeutic or surgical approaches are unsuccessful. Indications for corneal grafting include conditions with a distorted surface as in keratoconus, or with opacities such as in pseudophakic bullous keratopathy, corneal degenerations, corneal dystrophies, scars following infection or trauma. 
A high proportion of donor stromal cells can survive within the corneal transplant in the long-term. The proportion of surviving donor cells is highly variable; however, the source of this variability remains unknown (Lagali 2009b).

Due to a chronic worldwide shortage in donor corneas available for transplantation, much effort has been directed towards developing synthetic substitutes. Synthetic corneas such as Boston keratoprosthesis have been evaluated in cases where there have been several graft failures. More recently, extensive research has been performed to create biosynthetic corneas that better mimic native corneal tissue.

\section{Keratoprosthesis}

Artificial or synthetic corneas, are an option for transplant patients who reject human donor corneas or suffer from complex ocular disease. Although synthetic corneas (keratoprosthesis) have been used for over 50 years, the fabrication of synthetic stromal equivalents with the transparency, biomechanics, biocompatibility, and regenerative capacity of human donor corneas remains a formidable challenge.

The materials that have been evaluated for use as keratoprosthesis can be characterized as biological, synthetic and biosynthetic.

Biological materials include purified collagens I, III and IV (Kornmehl 1995). They promote re-epithelialization but there is high rate of degradation and lack of transparency (except collagen IV).

Synthetic materials are polymers cross-linked to form network; they promote biointegration of corneal tissue, but do not promote epithelialization (TrinkhausRandall 1997; Hicks 2000; Legeais 1998). 
Biosynthetic polymeric materials are a combination of synthetic bulk polymers complexed with appropriate biological materials such as collagen that aim to improve biocompatibility. Although collagen-synthetic copolymer have been synthesized using collagen and synthetic materials, these copolymers suffer from the same disadvantages as pure collagen lenticules in that they are susceptible to proteolysis in vivo.

The most successful biosynthetic constructs so far are based on cross-linked with water soluble carbodiimide human recombinant collagen III. They have been evaluated in humans and substituted donor corneas (Fagerholm 2010).

There are extensive possibilities to vary the composition of biosynthetic materials. Different types of collagen can be used as well as a wide variety of cross-linking techniques.

\section{PRK/ PTK and LASIK}

The most common laser refractive procedures performed today include ablative photorefractive keratectomy (PRK), laser epithelial keratomileusis (LASEK) and laser in situ keratomileusis (LASIK). Since excimer laser approval for use in the correction of myopia, refractive surgery has undergone considerable progress and development. However, despite these advances, complications do occur, particularly related to the somewhat unpredictable nature of corneal wound healing.

The surgical techniques and procedures for PRK involve epithelial removal before excimer ablation, therefore a large epithelial defect occurs (Taneri 2004). In LASEK the ablated epithelium is repositioned after the laser treatment (Dastjerdi 2002). The ablation of Bowman's layer and the anterior stroma and the subsequent epithelialstromal interactions lead to a wound healing response that can cause greater 
stromal haze and scarring than that in LASIK. Particularly in deeper ablations, corneal wound healing is a major contributor to some of the complications of PRK or LASIK (Azar 2012).

\section{Corneal wound healing models}

Wound healing models are important biological tools to understand basic processes of tissue repair and to develop and validate strategies for clinical treatment.

\section{In vitro models}

In vitro models of wound healing include cell culture, tissue engineered cornea and organ culture.

Cell culture used as wound model is usually either epithelial or corneal fibroblast confluent monolayer with wound created by scratching.

Tissue engineered cornea is a three-dimensional model which includes both epithelial and fibroblastic cells (Zaniolo 2013).

Organ culture is obtained by clamping of corneoscleral buttons in a specially designed chamber in such a way that epithelium is exposed to air and its anterior surface is automatically irrigated and endothelium is exposed to medium.

\section{Animal models}

Animal models are used in an attempt to reflect human wound healing problems.

For corneal wound models, rabbits and rats are the animals most commonly used.

Wound models used for in vivo studies depend on the aims and include ultraviolet radiation (UVR) exposure, incisional wound, surgical procedures such as PTK or suturing, alkali burn, and epithelial scraping or even transplantation. 


\begin{abstract}
Aims
The overall aim is to understand the role of keratocytes, and their phenotypic variations in a cornea subjected to various types of trauma.
\end{abstract}

Specific aims:

1. To define expression pattern of alpha-SMA and chaperonin containing Tcomplex polypeptide 1 (CCT) in an ultraviolet radiation wound model in rabbits.

2. To evaluate the effect of biglycan treatment during wound healing after corneal incision in rats.

3. To evaluate the effect of PRP treatment during wound healing after corneal incision in rats.

4. To characterize the structure of the bioengineered porcine construct and its interaction with stromal cells after implantation in rabbits. 


\section{Material and methods}

Animal models (papers I-IV)

All animal experiments were conducted according to the ARVO Resolution on the Use of Animals in Research. The experiments were performed following permission of the Linköping regional animal ethical board.

\section{Paper I}

Twenty-three adult female New Zealand albino rabbits were used. Five rabbits were used as a control group and did not receive any UVR treatment. The remaining 18 rabbits received intramuscular Ketalar (ketamine hydrochloride $25 \mathrm{mg} / \mathrm{kg}$; Pfizer AB, Täby, Sweden) and Rompun (xylazine $5 \mathrm{mg} / \mathrm{kg}$; Bayer AG, Leverkusen, Germany) anaesthesia prior to UVR exposure, and a lid speculum was put in place. One eye of each rabbit was exposed to UVR at $310 \mathrm{~nm}$ at a dose producing biomicroscopically significant keratitis $(0.47 \mathrm{~J} / \mathrm{cm} 2$, or 10 corneal threshold doses).

The fellow eye of each rabbit was not exposed to UVR, but was used as part of the control group. The corneal threshold doses to produce photokeratitis for different wavelengths were reported by Pitts (Pitts 1970; Pitts 1977). The UVR-exposed rabbits were divided into four groups. The first group (five rabbits) were killed with an overdose of pentobarbital i.v. 1 day after exposure. The second group (five rabbits) were killed after 2 days, and the third group (five rabbits) were killed 5 days after UVR exposure. The corneas were excised from the exposed and unexposed eyes without the scleral rims, and were stored in RNA stabilization reagent (RNAlater; QIAGEN, Hilden, Germany) until the RNA extraction. The fourth group (three animals) were killed 3 days after exposure. The corneas with a scleral rim were 
excised, fixed in $10 \%$ formaldehyde, embedded in paraffin, and sectioned at $5 \mu \mathrm{m}$. The corneal tissue specimens were processed for histological analysis using specific staining for $\alpha-S M A$.

\section{Papers II and III}

40 male adult Wistar rats weighing 315-385 g (Scanbur AB, Sollentuna, Sweden) were used for this study. Rats were anesthetized with $5 \%$ isofluorane in an anesthetic induction chamber and then with an intraperitoneal mixture of ketamine hydrochloride $(25 \mathrm{mg} / \mathrm{kg}$ ) and dexmedetomidine hydrochloride $(0.25 \mathrm{mg} / \mathrm{kg})$. Immediately prior to surgery, several drops of topical local anesthetic (tetracaine hydrochloride $1 \%$ eye drops; Chauvin Pharmaceuticals Ltd., UK) were placed on the eye. Under a surgical microscope, the central corneas were marked using 3-mm trephines (Miltex Inc., York, USA), and the corneal epithelium in the marked area was removed using a Beaver blade (MDSS Gmbh, Hannover, Germany). A diamond knife (Katena Products Inc., NJ, USA) was set to $150 \mu \mathrm{m}$ and used to make four incisions in the central corneal stroma forming a 'double cross' pattern (crossed pair of parallel horizontal and vertical incisions).

\section{Paper II}

For the control and experimental group (20 rats each), one drop of sodium chloride (9 $\mathrm{mg} / \mathrm{ml})$ or biglycan $(25 \mu \mathrm{g} / \mathrm{ml}$ in water), respectively, was applied topically to the wound immediately following incision. Five animals were sacrificed at each of four time points (4 hours, 1,3 , and 5 days) following incision. The entire corneas with a scleral rim of treated eyes were removed, fixed in $4 \%$ paraformaldehyde fixative solution, and embedded in paraffin. 
Paper III

For the control and experimental group (20 rats each), one drop of sodium chloride

(9 $\mathrm{mg} / \mathrm{ml})$ or platelet rich plasma (PRP) $(25 \mu \mathrm{g} / \mathrm{ml})$, respectively, was applied topically to the wound immediately following incision. Five animals were sacrificed at each of four time points ( 4 hours, 1,3 , and 5 days) following incision. The corneoscleral tissue of treated eyes were removed and fixed in $4 \%$ paraformaldehyde, and embedded in paraffin.

\section{Paper IV}

15 male New Zealand white albino rabbits (KB Lidkopings Kaninfarm, Vinninga, Sweden) weighing 3-3.5 kg were used. Animals were divided into three groups. In the first (control) group with 5 rabbits, native corneal tissue in one eye was cut intrastromally with a femtosecond laser but was kept in place and allowed to heal. In the second and third groups (5 rabbits each), the native corneal tissue in one eye was cut in an identical manner, but was thereafter excised and replaced with a bioengineered porcine construct (BPC). The second group received compressionmolded BPCs of $100 \mu \mathrm{m}$ thickness while the third group was implanted with swelled BPCs of $300 \mu \mathrm{m}$ thickness.

\section{Bioengineered porcine constructs (paper IV)}

1-ethyl-3-(3-dimethylaminopropyl) carbodiimide (EDC) and N-hydroxysuccinimide (NHS) were purchased from Sigma-Aldrich (St. Louis, USA). Porcine Collagen (typeI atelo-collagen) was kindly supplied by Sewoncellontech (Seoul, South Korea). Increased collagen content ( $18 \%$ collagen by weight) solutions were crosslinked using the water-soluble cross-linking agents EDC and NHS. These water soluble crosslinkers are so-called 'zero-length cross-linkers' that do not become incorporated 
in the final collagen scaffold (Yoeruek 2012). EDC and NHS were added to the collagen solution at equal molar ratios (1:1:1, EDC:NHS:collagen), mixed thoroughly and molded in between glass plates to make a homogeneous hydrogel scaffold. A $100 \mu \mathrm{m}$ thick spacer and a clamping system were used for compression molding of the $100 \mu \mathrm{m}$ thick implants. The same procedure was applied for the $300 \mu \mathrm{m}$ implants except that a compression molding was not used and the gel was allowed to swell during crosslinking. Samples were then cured at room temperature and then at $37^{\circ} \mathrm{C}$, in $100 \%$ humidity chambers. De-molding was achieved by immersion in phosphate buffered saline (PBS) for 1 hour. Samples were subsequently washed four times with PBS solution (1× PBS, containing $1 \% \mathrm{v} / \mathrm{v}$ chloroform) at room temperature to extract out reaction byproducts, and to sanitize the samples.

\section{Cell culture (paper II)}

Fresh bovine eyes were obtained from slaughter facilities with written consent of the Swedish Board of Agriculture. Bovine keratocytes were isolated using a sequential collagenase digestion method as described previously (Beales 1999). Cells were plated at density $1.5 \times 10^{5}$ cells $/ \mathrm{ml}$ in Dulbecco's minimum essential medium (DMEM/F12; Sigma, Stockholm, Sweden) containing antibiotic/antimycotic mixture to obtain corneal fibroblasts. Myofibroblastic phenotype was obtained by supplement of $2 \mathrm{ng} / \mathrm{ml}$ of TGF- $\beta_{1}$ (Sigma, Stockholm, Sweden) for at least 3 days. Media was changed every 2 to 3 days. Myofibroblast and fibroblast phenotypes were confirmed by staining with anti- $\alpha$ SMA antibody (Sigma, Stockholm, Sweden) and Alexa Fluor Signal Amplification Kit (Molecular Probes, Stockholm, Sweden) according to manufacturer's instructions. 
PCR (paper I, III)

Semi-quantitative RT-PCR was used for paper I and real-time PCR was used for paper III.

\section{Paper I}

RNA levels were semiquantitated by limiting-dilution reverse transcription polymerase chain reaction (RT-PCR) assay. To achieve this, sequence-specific primer pairs 17-22 base pairs (bp) in length were designed and purchased from Life Technologies (Paisley, UK).

The limiting-dilution technique is based on the principle that if two samples of RNA contain differing concentrations of a specific message, the sample with the higher concentration will support amplification of that message at a greater dilution. For each sample, one can determine a discrete end-point titration: the dilution at which no more molecules of the target RNA are present. The differing limiting-dilution points are proportional to the quantities of the specific message in the two samples. Thus, the process is not dependent on the efficiency of amplification.

To ensure that deoxyribonuclease (DNAse) treatment had removed any DNA contamination in the original preparations and that all amplification was supported by RNA only, each of specimens was run in a PCR-only reaction without reverse transcriptase.

The RT-PCR reactions for the limiting dilution analysis were performed using ReadyTo-Go RT-PCR Beads (Amersham Biosciences, Uppsala, Sweden). To determine the efficacy of the DNAse treatment, PCR was performed on $200 \mathrm{ng}$ of total RNA. The RNA quantities for each RT-PCR limiting-dilution experiment were titrated to 200, 100, 50, 12 and $3 \mathrm{ng}$. 
Paper III

Untreated cornea parts in RNAlater (QIAGEN, Sollentuna, Sweden) were frozen ($\left.80^{\circ} \mathrm{C}\right)$.

The expression of interleukin-1 $\beta$ (IL-1 $\beta)$ gene was investigated using real-time PCR. IL-1 $\beta$ mRNA expression was analyzed in each treatment group at each time point. Total RNA was extracted from corneas using RNeasy Mini Kit (QIAGEN, Stockach, Germany) and quantified using a NanoDrop spectrophotometer.

Following quantification, 150 ng of RNA was reverse transcribed to cDNA, and realtime quantitative PCR assay was conducted using an ABI PRISM 7500 real-time PCR System (Applied Biosystems, Foster City, CA, USA). PCR amplification was performed using the TaqMan Fast Advanced Master Mix (Life Technologies, Stockholm, Sweden). The PCR conditions for IL-1 $\beta$ consisted of 40 cycles of denaturation at $95^{\circ} \mathrm{C}$ for $3 \mathrm{~s}$ and annealing and extension at $60^{\circ} \mathrm{C}$ for $30 \mathrm{~s}$. Target mRNA levels were normalized to those of GAPDH. Gene expression was analyzed using the $2^{-\triangle \Delta C T}$ method.

Immunohistochemistry and immunocytochemistry (paper I-IV)

\section{Paper I}

After deparaffinization and rehydration in graded alcohol, the sections were incubated at room temperature for $30 \mathrm{~min}$ in $99.7 \%$ methanol containing $0.3 \%$ hydrogen peroxide to inhibit endogenous peroxidase. Slides were washed with Trisbuffered saline solution and blocked in diluted normal mouse serum. Tissue slides were incubated with primary mouse monoclonal antibody to a-SMA [1A4] (Abcam, Cambridge, UK) at a 1:50 dilution for $60 \mathrm{~min}$, and staining was then performed using the avidin-biotin peroxidase kit (Abcam) according to the manufacturer's instructions. 
Finally, slides were developed in AEC chromogen, counterstained with haematoxylin, dehydrated, cover-slipped, and examined under a conventional light microscope. Sections of normal, non-treated cornea were used as negative controls.

Papers II and III

Corneas were prepared with routine methods for paraffin sections and stained with hematoxylin and eosin (H\&E). Adjacent sections $(4 \mu \mathrm{m})$ from paraffin-embedded tissues were deparaffinized, trypsinized to retrieve antigen, and endogenous peroxidase was blocked with hydrogen peroxide in methanol. In Paper II, corneal sections were incubated with the primary antibody mouse monoclonal anti-a-SMA (dilution 1:100; Dako, Glostrup, Denmark) or anti-biglycan (dilution 1:100; Abcam, Cambridge, UK) for 30 minutes at room temperature. In paper III, corneal sections were incubated with the primary antibody mouse monoclonal anti- $\alpha$-SMA (dilution 1:100; Dako, Glostrup, Denmark), anti-SMAD2 [p Ser465, p Ser467] (dilution 1:200; Novus Biologicals, Sweden), or anti-SMAD3 [p Ser423, p Ser425] (dilution 1:500; Novus Biologicals, Sweden) for 30 minutes at room temperature. MACH 4 system was used to detect antibodies. The slides were incubated with a MACH 4 mouse probe (Biocare Medical, Goteborg, Sweden) for 10 minutes at room temperature, treated with MACH 4 HRP polymer (Biocare Medical, Goteborg, Sweden), and the nuclei were counterstained with Mayer's hematoxylin. The sections were mounted and observed by microscopy ( 3 adjacent sections of each cornea). 5 intact corneas were stained as negative control.

Fragmentation of DNA associated with apoptosis was detected by a fluorometric method (DNA fragmentation detection kit II (BrdU); PromoKine, Stockholm, Sweden). The assay was performed according to the manufacturer's instructions 
using paraffin embedded tissue sections adjacent to those used for immunohistochemistry. Stained sections were mounted in an aqueous mounting medium and observed using a laser-scanning confocal fluorescence microscope (Nikon Eclipse E600).

\section{Paper IV}

Following sacrifice, eyes were enucleated and corneas were removed using surgical scissors, fixed in $4 \%$ paraformaldehyde fixative solution, and embedded in paraffin. Corneas were prepared with routine methods for paraffin sections $(4 \mu \mathrm{m})$ and stained with $H$ \& E. Sections from paraffin-embedded tissues were deparaffinized with descending concentrations of ethanol and xylene, trypsinized for $5 \mathrm{~min}$ to retrieve antigen, and endogenous peroxidase was blocked with $3 \%$ hydrogen peroxide in methanol.

Corneal sections were incubated with the following primary antibodies for 30 minutes at room temperature: mouse monoclonal anti-alpha smooth muscle actin monoclonal antibody, a-SMA (dilution 1:25; ab7817, Abcam, Cambridge, UK); mouse monoclonal anti-type I collagen (1:50; ab6308, Abcam); mouse monoclonal anti-type III collagen (1:100; AF5810, Acris Antibody GmbH, Germany); mouse monoclonal anti-leukocyte common antigen CD45 (1:400; M0701, Dako Sweden AB, Stockholm). The slides were then incubated in envision HRP for 30 minutes following antibody application. 3, 3'-diaminobenzidine (DAB) liquid chromogen was applied for 10 minutes to all samples, and all sections went under counter staining with hematoxylin. Samples were dehydrated through ascending concentrations of ethanol and were finally cleared in xylene and coverslipped with Mountex mounting medium (Histolab Products AB, Gothenburg, Sweden). 
For double immunofluorescent staining, samples were prepared as for immunohistochemistry but replacing the endogenous peroxidase blocking step with $5 \%$ normal goat serum (Jackson ImmunoResearch Europe, Newmarket, UK). Samples were incubated with the first primary antibody (type III collagen, 1:100) for 30 min. Samples were then rinsed in PBS, blocked, and incubated with the secondary antibody for 30min (goat anti-mouse Dylight 549, 1:100, Jackson ImmunoResearch Europe, Newmarket, UK).

This procedure was then repeated with 5\% normal donkey serum (Jackson), applying the second primary antibody ( $\alpha-S M A$ or CD45) and secondary antibody (donkey anti-mouse Dylight 488, 1:300, Jackson). Imaging was performed using a laser-scanning confocal fluorescence microscope (Nikon Eclipse E600) equipped with $40 x / 1.30$ NA oil-immersion or 20x/0.75 NA objective lenses. Samples were scanned under single or dual laser excitation and a digital camera was used to record images.

In all cases, control samples were used and omission of the primary antibody eliminated cell specific staining.

\section{Cell count (paper II, III)}

Stromal cell numbers in control and biglycan treated corneas were assessed by counting the total number of cells along with the number of positively stained cells in corneal sections. Sections were taken from five corneas in each treatment group at each time point. Two sections per cornea were analyzed, and within each section, 3 to 6 fields of view of stromal tissue around the wound site at 20x magnification were included. 
Electron microscopy (paper IV)

TEM

For transmission electron microscopy (TEM), BPC materials prior to implantation were removed from chloroform solution, soaked overnight in PBS, and fixed in glutaraldehyde (2\% glutaraldehyde, $0.1 \mathrm{M} \mathrm{Na}$ cacodilate, $0.1 \mathrm{M}$ sucrose, $\mathrm{pH} 7.4)$ at $4^{\circ} \mathrm{C}$ and post fixated with $1 \%$ osmium tetraoxide in $0.15 \mathrm{M}$ sodium cacodylate buffer. Resin infiltration and embedding were performed by first dehydrating samples in ascending concentrations of ethanol followed by incubation with propylenoxide for one hour. Gradual infiltration of Epon 812 resin (TAAB, Reading, England) was initiated by incubation of samples in a propylenoxide/Epon (1:1) solution for 2 hours and infiltration in Epon overnight. The samples were placed in Epon and cured in an oven at $60^{\circ} \mathrm{C}$ for 48 hours to polymerize. Ultrathin (60nm) sections for TEM analysis were cut by a diamond knife, placed on copper grids, and stained with uranyl acetate-lead citrate. TEM sections of the implant material were observed with a transmission electron microscope (Model JEM-1230, JEOL Ltd., Tokyo, Japan).

For post-implantation ex-vivo analysis, corneal tissue containing implant material was fixed in $4 \%$ paraformaldehyde in $0.1 \mathrm{M}$ phosphate buffer PBS. The tissue was then washed and further fixed in $2.5 \%$ glutaraldehyde containing $0.05 \%$ cuprolinic blue (BDH Ltd, Dorset) using a critical electrolyte concentration mode in $25 \mathrm{mM}$ sodium acetate with $0.1 \mathrm{M}$ magnesium chloride buffer overnight at room temperature. The tissue was then dehydrated through a graded ethanol series (50\% to 100\%) and $100 \%$ acetone. They were then immersed in a mixture of acetone and Spurr's resin for 8 hours. The tissue was further immersed in 100\% Spurr's resin for 8 hours (x3) and polymerized in Spurr's resin for 8 hours at $60^{\circ} \mathrm{C}$. Ultrathin sections were cut from the polymerized block and these sections were collected on 200 mesh copper grids. 
Ultrathin sections were stained with $2 \%$ uranyl acetate and $2 \%$ lead citrate. Sections were observed by transmission electron microscope (Model JEM-1400; JEOL Ltd, Tokyo, Japan).

\section{SEM}

Human donor eye bank corneas were obtained with ethical permission from the Eye Bank of Canada. The morphology was investigated using a scanning electron microscope (SEM, Model S-2250N, Hitachi, Japan). The bioengineered corneas were imaged using a ZEISS SEM (LEO 1550 Gemini). PBS-equilibrated samples were frozen over night at $-80^{\circ} \mathrm{C}$ and then lyophilized for $6 \mathrm{hrs}$. The samples were cut out and attached onto metal holders using conductive double-sided tape, and sputter coated with a gold layer for 60 seconds at 0.1 bar vacuum pressure (Cressington Sputter Coater, 108) prior to SEM examination. SEM micrographs were taken at various magnifications at $25 \mathrm{kV}$ and $5 \mathrm{kV}$ for human and bioengineered corneas, respectively.

In vivo confocal microscopy (paper IV)

IVCM images were obtained by a technique described in detail elsewhere (Lagali 2013). Briefly, the instrument's microscope objective (63x/0.95 NA immersion, Zeiss, Oberkochen, Germany) was placed in contact with the topically anesthetized (tetracaine hydrochloride 1\%, Chauvin Pharmaceuticals Ltd., UK) rabbit corneal surface by means of a gel coupling medium (Viscotears, carbomer $0.2 \%$, Dr Mann Pharma, Berlin, Germany). The focal depth in the cornea was then adjusted by a joystick-driven motor, to image the epithelium, subbasal nerves, stroma, and endothelium, while manual controls were used to translate the microscope objective to image both the central and peripheral implanted regions. 
Images were acquired automatically at 8 frames/s and saved directly to hard disk for later retrieval and analysis.

Anterior segment optical coherence tomography (OCT) (paper IV)

Immediately following operation, operated eyes were examined in vivo by OCT to assess the femtosecond laser-created pocket and confirm the intra-stromal location of inserted BPC implants. At 2, 5, and 8 weeks postoperatively, all animals were examined under general anesthesia by OCT, high-magnification digital photography (Nikon D90 camera, Nikon Canada Inc., Toronto, Canada).

At each examination session, OCT images were taken depicting the same central cross-section of the operated cornea, in high resolution mode.

Statistical analysis (paper I-IV)

Paper I

Kruskal-Wallis one-way analysis of variance was used for testing the difference between the groups. The probability $(p)$ level of $<0.05$ was considered significant.

Paper II

Statistical analysis was performed by one way or two way analysis of variance (ANOVA) for in vitro and in vivo data, respectively, using SigmaStat software (Systat Inc., Chicago IL, USA). Two-tailed probability values of less than 0.05 were considered significant.

Paper III

Statistical analysis of apoptosis, myofibroblasts, SMAD2/3 and IL-1 $\beta$ was performed by two way analysis of variance (ANOVA) with time after wounding and treatment as independent factors using SigmaStat software. Two-tailed probability values of $\alpha<$ 
0.05 were considered significant. To isolate differences of multiple comparisons, the Holm-Sidak method was used as a post-hoc test.

\section{Paper IV}

Central corneal thickness as assessed by OCT, was compared over time and between groups using two-way analysis of variance (ANOVA), with time and implant type as independent variables. Post-hoc multiple comparisons were performed with the Student-Newman- Keuls method to isolate specific differences. A two-tailed significance level of less than 0.05 was considered significant. All statistical tests were performed using Sigma Stat 3.5 statistical software. 


\section{Results}

\section{Paper I}

There was slight chaperonin containing T-complex polypeptide 1 (CCT) gene expression and no $\alpha$-SMA expression in the control group (untreated rabbits). One day after UVR exposure, the a-SMA gene was strongly expressed, whereas the expression level of CCT chaperonin was slightly increased $(p<0.05)$. Two days after exposure, the CCT chaperonin gene was strongly expressed $(p<0.01)$ with the expression decreasing at 5 days after exposure $(p<0.05)$ (Fig.2).

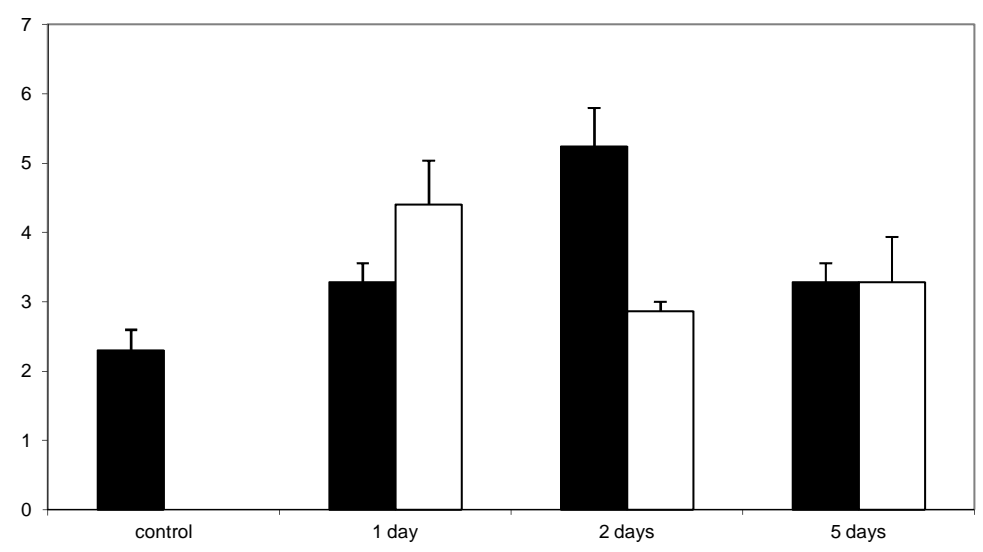

Figure 2. Levels of CCT chaperonin subunit (black bars) and alpha-SMA (white bars) expression in the rabbit cornea after UVR exposure. The levels of expression (y axis) were calculated as $\ln d^{-1}$ where $d$ is the end-point dilution. Means \pm SEM are shown. Untreated rabbits were used as control group. 


\section{Paper II}

\section{Effect of Biglycan on Survival of Corneal Cells}

Quantification of histone-associated DNA fragments by the cell death detection ELISA was performed in cell culture. It revealed a significantly elevated apoptosis ( $p$ $<0.001$ ) after the addition of IL-1 $\beta$ in corneal myofibroblast but not in fibroblast cell cultures (Fig. 3A). Co-incubation with biglycan induced a further significant increase in apoptosis of myofibroblasts (but not fibroblasts), relative to IL-1 $\beta$ treated and control cultures ( $p=0.038$ and $p=0.002$, respectively).

\section{Death of Corneal Stromal Cells in vivo after incisional injury}

In the control group, a high percentage of BrdU positive cells $(95.0 \pm 5.5 \%)$ was present at the wound site 4 hours following wounding, but BrdU positivity decreased significantly by day $1(p<0.001)$ and declined further by day $3(p=0.024$ relative to day 1). A second peak of apoptosis occurred at day 5 ( $p<0.001$ relative to day 3$)$. In biglycan treated corneas, the percentage of apoptotic stromal cells at 4 hours after wounding was $70.0 \pm 19.2 \%$, and decreased significantly from 4 hours to day 1 ( $p<$ $0.001)$. A second peak of apoptosis was apparent at day $3(p=0.006$ relative to day 1) (Fig. 3B).

The biglycan treated corneas exhibited a lower percentage of apoptotic stromal cells at 4 hours, day 1 and day 5 relative to controls $(p=0.012,0.040$, and 0.048 , respectively), and a higher percentage at day $3(p=0.003)$.

There were no BrdU positive stromal cells in intact corneas. 

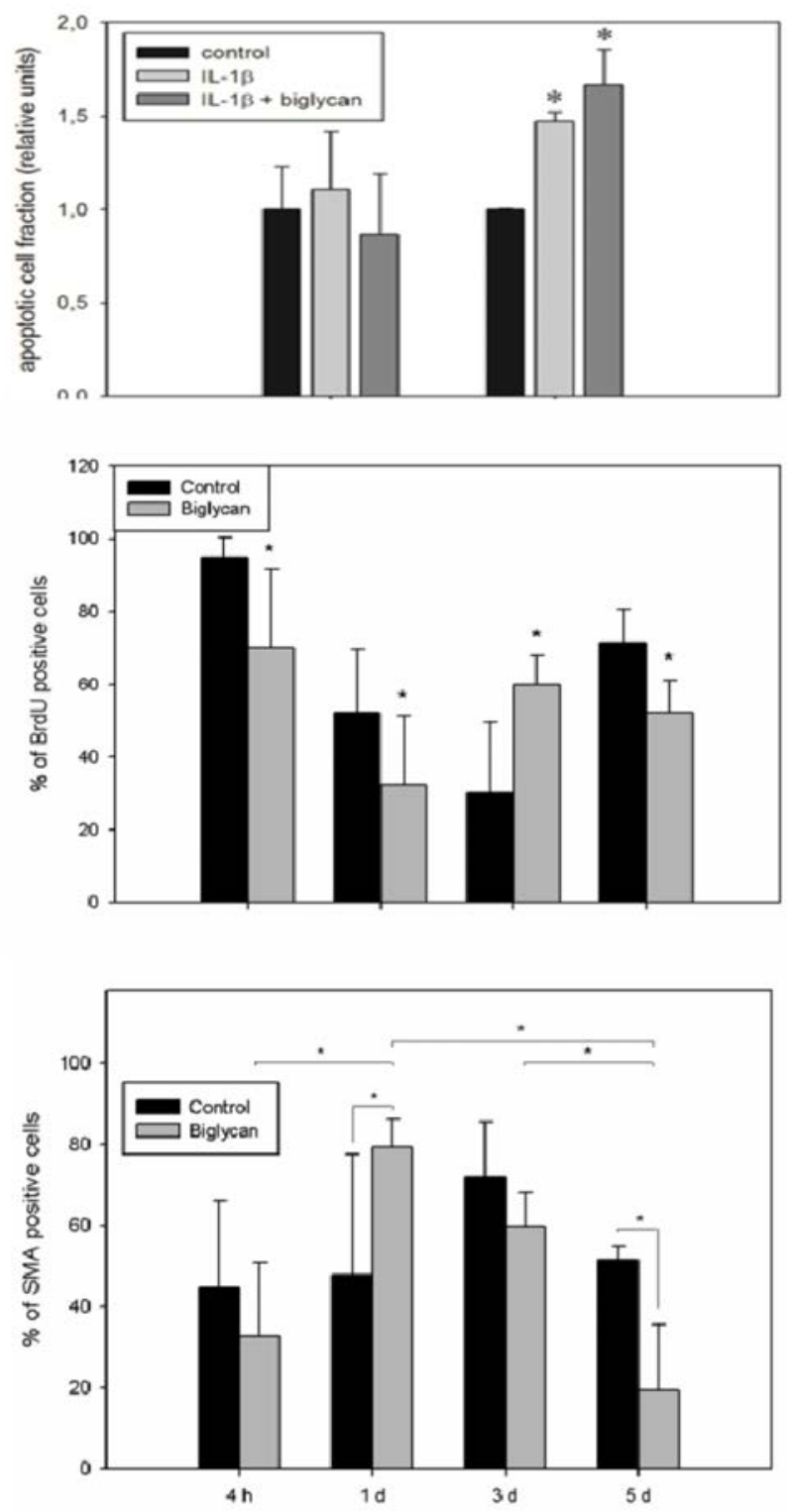

C

Figure 3. (A) Effect of biglycan on IL-1 $\beta$ induced corneal stromal cell death in vitro (left and right charts present data on fibroblast and myofibroblast cell culture respectively). (B) The percentage of apoptotic cells. (C) The percentage of $\alpha$-SMA positive cells. ${ }^{*} \mathrm{p}<0.05$. 
The proportion of $\alpha$-SMA positive to total stromal cells did not change significantly during the wound healing period in the control group. In biglycan-treated corneas, the proportion of $\alpha$-SMA positive cells increased significantly from 4 hours to day 1 , then decreased significantly from day 3 to day 5 ( $p<0.001$ for both). A greater proportion of $\alpha$-SMA positive stromal cells was present at day 1 and a reduced proportion was present at day 5 in biglycan treated corneas, relative to the control group ( $p=0.006$ and 0.005 , respectively). There were no $\alpha$-SMA positive cells in intact corneas (Fig. 3C).

Paper III

Death of Stromal Keratocytes in injured corneas , the influence of platelet rich plasma $(P R P)$

In the control group, a high proportion of BrdU positive cells was present after 4 hours. This proportion decreased at day $1(p<0.001)$ and day $3(p=0.024$, relative to 4 h). A second peak of apoptosis occurred at day 5 ( $p<0.001$ relative to day 3 ).

In PRP treated corneas, the percentage of apoptotic stromal cells decreased significantly from 4 hours to day $1 ;(p<0.001)$ and further to day $3(p=0.007$ relative to day 1). There was no significant difference in apoptosis between days 3 and 5 in the PRP treated group. The PRP treated corneas exhibited reduced apoptosis at 4 hours relative to controls, and additionally a statistically significant reduction was observed at day 3 and day 5 relative to controls ( $p=0.038$, and $<0.001$, respectively) (Fig. 4A). 
$\alpha$-SMA Positive Stromal Cells in Healing Corneas after PRP Treatment

A greater proportion of $\alpha$-SMA positive stromal cells (myofibroblasts) was present at 4 hours (74 $\pm 7 \%$ vs $45 \pm 19 \%)$ and at day 5 (93 \pm 6 vs $52 \pm 3 \%$ ) in PRP treated corneas, relative to the control group ( $p=0.006$ and $<0.001$, respectively). The proportion of $\alpha$-SMA positive to total stromal cells did not change significantly during the wound healing period within either group (Fig. 4B).

A



B



Figure 4. Changes in survival $(A)$ and phenotype $(B)$ of stromal cells in wounded corneas after PRP treatment compare to control corneas. 
Changes of IL-1 $\beta$ Expression by the Effect of PRP

To investigate whether a decrease of apoptosis in the PRP treated group could be explained by suppression of IL-1 $1 \beta$ expression, we analyzed IL-1 $1 \beta$ expression by real time PCR. During wound healing, no significant difference in IL-1 $\beta$ expression was observed between groups over time. In both PRP treated and control group, peak expression of IL-1 $\beta$ occurred at day 1 , followed by a significant reduction at days 3 and 5.

pSMAD2/3 Positive Cells in Healing Corneas after PRP Treatment

The proportion of pSMAD2 positive cells in control corneas, increased significantly from 4 hours $(16 \pm 8 \%)$ to day 1 (50 $\pm 3 \% ; p=0.007)$, and remained significantly elevated until day 5 . The proportion of pSMAD2 positive to total stromal cells did not change significantly during the wound healing period in the PRP treated group. There was no statistically significant difference between PRP treated and control corneas.

The proportion of pSMAD3 positive cells increased significantly in control corneas from 4 hours $(48 \pm 16 \%)$ to a peak at day 1 ( $86 \pm 8 \%$; $p=0.008)$, then decreased at day 3 (38 $\pm 10 \% ; p=0.002$, relative to day 1$)$ and decreased further by day $5(1 \pm 2 \%$; $\mathrm{p}=0.01$, relative to day 3 ). Relative to controls, pSMAD3 positive cells in PRP treated corneas were reduced at day $1(86 \pm 8 \%$ vs $37 \pm 11 \% ; p=0.001)$, and dramatically increased at day $5(1 \pm 2 \%$ vs $34 \pm 13 \% ; p=0.032)$. In the PRP treated group, the proportion of pSMAD3 positive cells did not change significantly during the wound healing period. 


\section{Paper IV}

Structural properties of bioengineered porcine constructs (BPCs)

Microstructure of a dehydrated human cornea by scanning electron microscopy (SEM) revealed lamellae parallel to the corneal surface, with periodic attachments between layers occurring with $20-100 \mu$ m periodicity.

The BPC microstructure by contrast did not consist of lamellae but of a fine, porous collagen structure sandwiched between two dense surface layers, similar to the


membrane of the human cornea. Pore size within the BPC ranged from submicron to $2 \mu \mathrm{m}$ in diameter. Ultrastructural analysis of the BPC by transmission electron microscopy (TEM) revealed a relatively sparse and disorganized, nonlamellar arrangement of collagen fibrils. Fibrils had varying sizes but were typically $30-40 \mathrm{~nm}$ in diameter. Local variations in collagen fibril density were apparent; in some regions, fibrils were not detected, but instead nanometer-sized, electron-dense particulate matter was apparent. The possibility, however, could not be excluded that variations in collagen fibril size and density were a sampling phenomenon attributed to the random orientation of the collagen fibrils within the scaffold.

Femtosecond laser-enabled intrastromal keratoplasty (FLISK) maintains the host cellular environment while BPCs integrate and attract host cells in vivo

Corneal examination at the cellular level by IVCM revealed that during the postoperative period, the anatomic structures of the cornea outside the implanted zone were left undisturbed by the surgery or by the presence of the BPC. All anatomic layers including epithelium, subbasal epithelial (sensory) nerves, stromal keratocytes and endothelium were detected and exhibited normal morphology at 8 
weeks postoperative. Moreover, no inflammatory cells could be observed in vivo. Within the surgical zone, laser cut interfaces (autograft) or implant host interfaces (anterior, posterior and lateral) were marked by light-scattering cells (activated keratocytes and fibroblasts) and light-scattering tissue (fibrous scar tissue). Within the center of the surgical zone in autografts, slight activation and deformation of stromal keratocytes were evident. The center of the BPC implants remained unpopulated by cells at 8 weeks. Some cells, however, were observed within the BPCs in peripheral areas near the host-to-biomaterial implant border.

BPCs enable rapid wound healing without inflammation, and initiate stromal regeneration by host myofibroblast recruitment

In autografts, where tissue was laser cut (but not extracted), remnants of the lamellar laser incisions were visible. In autografted corneas, minimal presence of $\alpha$-SMA+ stromal myofibroblasts or type III collagen (scar-type collagen) was found at the lamellar interfaces, and no CD45+ leukocytes were observed around the surgrical zone. In corneas with BPCs, the BPC was discernible by its homogeneous and acellular appearance. BPCs remained intact and integrated with surrounding host tissue, with a-SMA+ stromal myofibroblasts often observed in close apposition to anterior and posterior lamellar interfaces. These myofibroblasts appeared in regions where type III collagen was present. No CD45+ leukocytes were observed in or around the BPCs. To determine whether the myofibroblasts were the source of the type III collagen and to confirm the absence of inflammatory leukocytes, colocalization of $\alpha$-SMA/type III collagen and type III collagen/CD45 was investigated by double immunofluorescent staining. At anterior and posterior lamellar interfaces, a-SMA+ myofibroblasts, in close proximity to and often in direct contact with the BPC, co-localized with new type III collagen. No strong CD45+ signal was observed, 
indicating no association of new collagen production with leukocyte invasion. Closer inspection of the BPC periphery in H\&E and immunostained sections indicated migration of a limited number of stromal cells into the implant at 8 weeks postoperative. Cells appeared to migrate into BPCs in single file through narrow tunnels, single cells appeared deeper within the BPC, or cells appeared to invade the BPC from peripheral locations. These cells were associated with the production of type III collagen within the implants, and a limited transformation of BPC collagen into host collagen was visible in H\&E stained sections.

BPCs contain proteoglycans but no detectable collagen fibril structure or lamellae despite maintaining transparency in vivo

At 8 weeks postoperative, ex vivo transmission electron microscopy of implanted corneas revealed the lamellar laser-cut interface as a dark, electron-dense demarcation line. On the host side of this line, a band of tissue with disrupted fibril structure interspersed with dark vacuoles corresponding to the location of newly formed type III collagen. Stromal cells with well-developed nuclei and endoplasmic reticulum were observed in association with the modified collagen band, and close to the implant-to-host interface corresponding to the location of a-SMA positive fibroblasts (myofibroblasts).

Outside this band, tightly-packed and perpendicularly-oriented collagen fibrils within lamellae were visible and were characteristic of the normal, native corneal stroma. The BPC, however, consisted of a homogeneous, non-lamellar ultrastructure. Even at high magnification, no collagen fibril structure was observed within the BPC, while electron lucent spaces were present. Proteoglycans (analyzed in TEM sections not stained with uranyl acetate and lead citrate) in the host stroma were regularly arranged around parallel-running collagen fibrils. Unexpectedly, the BPC also 
contained proteoglycans; however, these were randomly distributed and collagen fibrils could not be discerned. 


\section{Discussion}

Corneal tissue response to injury involves the activation and myofibroblast transformation of keratocytes, which can result in the expression of actin by these cells. This response is non-specific to the type of injury (Lee 2001; Ishizaki 1994). In vitro studies have suggested that myofibroblasts are an important phenotypic cells playing role in wound healing and haze/scar formation (Masur 1996; Jester 1999c; Wilson 2012).

It is important to distinguish pathological late haze associated with myofibroblasts from the mild haze that occurs in nearly all wounded corneas including those with perfect clinical outcomes. The more common, clinically insignificant haze is not attributable to myofibroblasts, and the excessive extracellular matrix they produce, but likely also to a transient edema or to corneal fibroblasts that are opaque due to decreased corneal crystallin production and alterations to extracellular matrix materials (Jester 1999b). An inhibitory effect on both corneal fibroblasts and myofibroblasts proliferation may be beneficial for pathological haze prevention (Fig. $5)$.

Our results (Paper I) allow us to suggest that $\alpha$-SMA formation is one step in the wound-healing process. After $\alpha$-SMA is expressed, its denatured form has to be folded to a correct and functional structure. This process is mediated by CCT, the chaperonin present in the eukaryotic cytosol (Sternlicht 1993). 

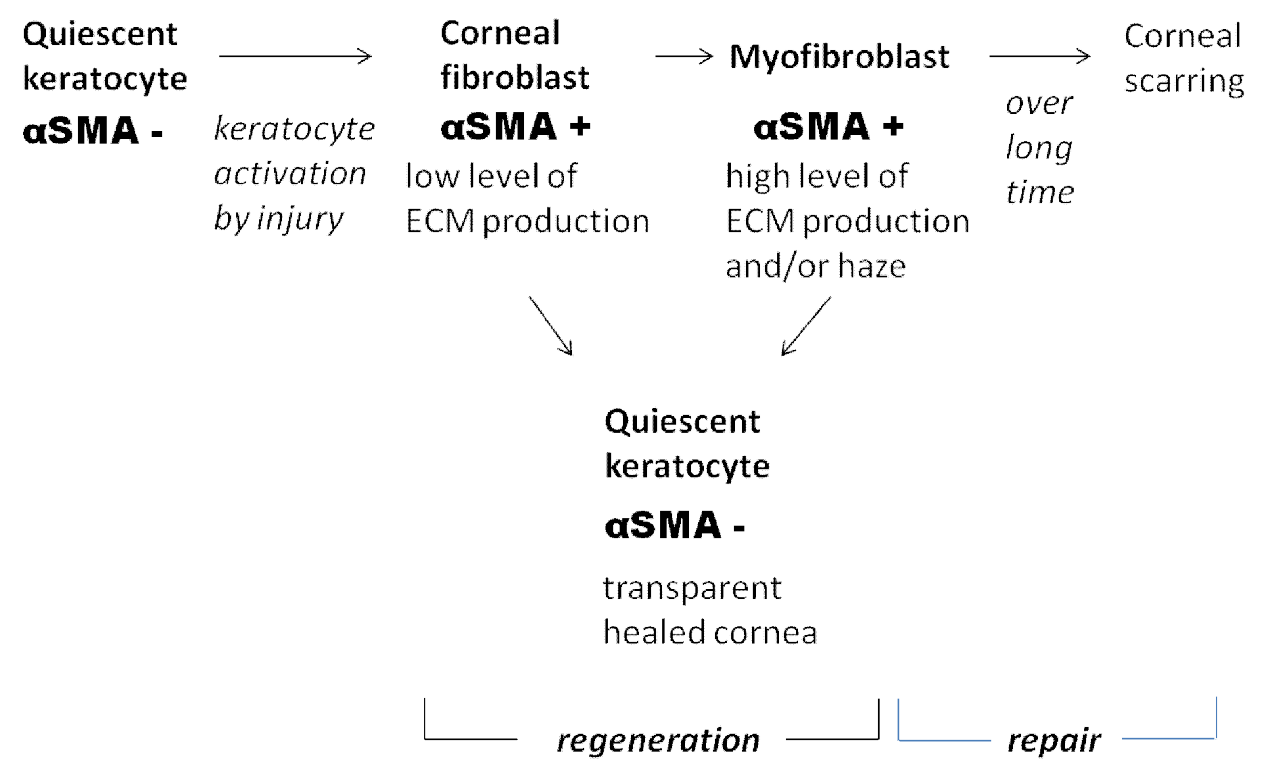

Figure 5. Schematic presentation of corneal stromal cell types during wound healing.

Alpha-SMA was expressed at mRNA level within 24 hours of injury to the corneal stroma. The increase in the expression of the CCT at mRNA level was detected after 48 hours. The expression of a-SMA protein was found in the keratocytes repopulating the stromal wound volume at day 3. By 5 days, the expression of both mRNAs had declined. This suggests that co-ordinated up-regulation of the a-SMA and CCT chaperonin in repopulating keratocytes may promote the formation of myofibroblasts by the folding of a-SMA to form the stress fibres characteristic of these cells. The formation of myofibroblasts occurs even after mild injury when the cornea heals to transparency, indicating the importance of this step in corneal wound healing.

Up-regulation of CCT chaperonin might be associated with functions other than actin folding. Beside cytoskeletal proteins, CCT was recently found to be essential for the 
maturation of human cyclin $\mathrm{E}$, a positive regulator of the G1-to-S phase transition in the mammalian cell cycle (Won 1998).

Finally, up-regulated expression of one CCT subunit does not necessarily mean an increased amount of functional chaperonin. Roobol \& Carden (Roobol 1999) contended that changes in the levels of various subunits are not necessarily coordinated. Thus, some subunits may have additional functions besides participating in actin folding as part of CCT, and may be individually regulated for separate reasons.

Myofibroblast apoptosis has an important role in the regulation of corneal haze through the removal of the cellular contribution to the opacity (Wilson 2007). In vivo (Paper II), results from the control group indicated that an early apoptosis of primarily a-SMA negative keratocytes and fibroblasts occurred at 4 hours, then decreased at day 1. At day 3, a-SMA positive myofibroblasts assembled at the wound site, and then underwent apoptosis at day 5. Topical biglycan modified the early apoptotic phase by suppressing the early apoptosis of keratocytes and fibroblasts at 4 hours relative to controls. Consequently, an earlier significant increase in the number of $\alpha$ SMA positive myofibroblasts derived from the existing keratocytes and fibroblasts was evident at day 1 relative to controls. These myofibroblasts underwent apoptosis at day 3 (instead of day 5 as in the control group), resulting in a significant reduction in myofibroblasts presence at the wound on day 5 relative to controls. We therefore suspect that the early suppression of apoptosis by topical biglycan treatment accelerated the subsequent wound healing cascade, such that $\alpha$-SMA positive myofibroblasts appeared at the wound earlier, and were removed earlier, relative to the control group. 
There is no expression of endogenous biglycan in the normal cornea, but its significant expression after injury has been shown (Podskochy 2004). Therefore, biglycan might be an important factor in the restoration of corneal transparency after the initial wound healing response. This suggestion is supported by an earlier report of a transgenic mouse model mimicking congenital stromal corneal dystrophy which showed corneal opacities and down regulated expression of endogenous biglycan (Chen 2011).

Our study (Paper II) shows that biglycan enhances IL-1 $\beta$ induced apoptosis of stromal myofibroblasts in culture. Moreover, topical biglycan treatment appeared to accelerate corneal wound healing by early inhibition of keratocyte and fibroblast apoptosis and subsequent myofibroblast removal in vivo. We therefore suggest that biglycan deserves attention as a possible therapeutic agent.

In our study (paper III), we report the effects of PRP in a corneal incision wound model. BrdU staining demonstrated that PRP inhibits apoptosis of stromal cells. A similar pattern was observed, where repeated UVR exposures led to keratocytes resistance to apoptosis (Podskochy 2001). Interestingly, a significant increase in the proportion of a-SMA positive stromal cells in PRP treated corneas, particularly at day 5 , was consistent with suppressed apoptosis at days 3 and 5 .

Previous studies have shown the potential of plasma rich in growth factors (PRGFEndoret) to inhibit fibroblasts from transforming to myofibroblasts, while other cellular processes involved in wound healing such as fibroblast proliferation and migration are enhanced (Anitua 2012a; Anitua 2012b; Anitua 2011; Anitua 2013a; Anitua 2013b; Anitua 2013c). PRP on the other hand, has been shown to promote proliferation, and induces differentiation of human dermal fibroblasts into myofibroblasts (Kushida 2013). Despite reported successes, some researchers have 
raised concerns that PRP treatment may induce a fibrotic healing response in tissues (Borrione 2010; Giovanini 2011; Terada 2013). The authors suggested that PRP induced an effect similar to a fibroproliferative disorder, and attributed this effect to TGF- $\beta$ autocrine secretion by myofibroblasts, that can promote and maintain the myofibroblast differentiated state while simultaneously inhibiting apoptotic stimuli.

It was suggested that interleukin-1 (Wilson 1996) released from injured epithelial cells induces keratocyte apoptosis. In this study (Paper III), there was no significant difference in IL-1 $\beta$ mRNA expression between PRP treated and control group, indicating IL-1 $\beta$ independent apoptosis induction. The mechanisms involved in apoptosis of myofibroblast progenitor cells, however, could be passive. For example, bone marrow cells in the corneal stroma could undergo apoptosis when deprived of interleukin-3 (IL-3) that maintain cell viability (Rodriquez-Tarduchy 1990). The IL-3 deprivation as well as IL-1 $\beta$ stimulation is accompanied by caspase 3 activation (Ohta 1997). However, more active processes could be present to remove cells that are not needed, perhaps modulated by cytokines derived from the healing epithelial or stromal cells.

Among all potential cytokines, TGF- $\beta$ is the most potent in up-regulating the $\alpha$-SMA. It has been shown that effective suppression of the TGF- $\beta$ signalling system prevents myofibroblast differentiation and in this way can reduce scarring (Tseng 1999).

A possible explanation for accumulation of a-SMA positive cells at day 5 (Paper III) would be a high level of TGF- $\beta$, which is known to stimulate fibroblast differentiation into myofibroblasts (Wilson 2012). We tested activation of the TGF- $\beta$ pathway by immunohistochemical staining for SMAD2 and SMAD3. SMAD3 (but not SMAD2) 
phosphorylation, was strongly up regulated at day 5 in the PRP treated group. Although preliminary, these results implicate the TGF- $\beta$ pathway as one likely target of PRP. It appears that PRP treatment resulted in sustained TGF- $\beta$ signaling in our model, however, the consequences of this prolonged signaling are unclear. Given that myofibroblasts are increased in cell volume and synthesize fibrotic, scar-type collagen, their sustained presence in large numbers could contribute to corneal haze or scarring. Although scarring was not apparent over the duration of our in vivo experiment, longer follow-up or possibly a more aggressive wound model could elucidate the impact of the sustained myofibroblast population on scar development and long-term corneal transparency.

We observed (paper III) suppressed apoptosis followed by SMAD3 activation and prolonged myofibroblast accumulation in PRP treated corneas compared to controls. Suppression of stromal cell apoptosis after corneal wounding by use of a growth factor rich formulation may lead to myofibroblast accumulation by modulation of the TGF- $\beta$ pathway. More rigorous studies on the effect of PRP in the cornea are required; however, this study highlights that a growth factor rich formulation may not necessarily be beneficial in certain wound healing situations.

In our study (Paper IV) the BPC, formulated from cost-effective medical-grade porcine collagen, has shown the potential to fulfill biocompatibility criteria. We observed transformation of keratocytes, migration of myofibroblasts into the BPC, and production of type III collagen which is part of a normal healing process (Fig.5). Despite the significantly higher strength, toughness, elasticity, and resistance to collagenase degradation exhibited by the human cornea compared to BPCs, our in vivo data suggest it may not be desirable for bioengineered materials to closely mimic the mechanical characteristics of the native cornea. While human donor 
corneal tissue (or de-cellularized porcine corneas) may take years to degrade or become cell-repopulated after transplantation (Lagali 2009b), here we observed an early cell migration into BPCs and initial collagen transformation only 8 weeks after implantation. Although the migration was limited, with longer follow-up, increased cell invasion is to be expected. We observed for the first time to our knowledge, a bioengineered material capable of inducing corneal stromal regeneration in vivo by host stromal cell recruitment.

An unexpected result in our study was the absence of an ordered arrangement of intact collagen fibrils in the $100 \mu \mathrm{m}$ thick BPCs, despite their transparency. The prevailing theory for the physical origin of corneal transparency is that collagen fibrils are spaced regularly in three dimensions and that the distance between the collagen fibrils is similar to the diameter of a fibril itself (Silver 1999; Hassell 2010). By these criteria, the BPC microstructure should render the material opaque; however, the BPC had a transmission superior to the human donor cornea in vitro, and similar transparency to autografts (native rabbit tissue) in vivo, despite a porous, nonlamellar architecture and absence of collagen fibril ultrastructure. Moreover, proteoglycans were distributed througout the BPC, which are thought to play a role in maintaining corneal transparency by regulating the assembly of collagen fibrils and organization of the extracellular matrix (Michelacci 2003). The origin of the transparency of the BPC and the composition of the proteoglycans bound within its matrix warrants closer investigation.

Taken together, results from papers II and IV present an interesting possibility to combine BPC implantation and topical biglycan treatment to improve surgical outcome in future studies. 


\section{Conclusions}

1. In a mild wound, the expression of $\alpha$-SMA mRNA is followed by expression of mRNA of at least one subunit of the complex folding $\alpha$-SMA. At protein level, a-SMA is detected in the front line of repopulating keratocytes. Expression levels for both mRNAs decline as the stroma repopulation process progresses.

2. Biglycan appears to accelerate corneal wound healing in vivo by modulating myofibroblast apoptosis, resulting in removal of myofibroblasts that may otherwise compromise corneal transparency.

3. PRP treatment resulted in suppressed stromal cell apoptosis followed by SMAD3 activation and a greater proportion of myofibroblasts present at the wound site. Suppression of stromal cell apoptosis after corneal wounding by use of a growth factor rich formulation may lead to myofibroblast accumulation by modulation of the TGF- $\beta$ pathway.

4. A cost-effective BPC extracellular matrix equivalent can incorporate cells passively to initiate normal regenerative healing of the corneal stroma. 


\section{Acknowledgements}

I wish to express my most sincere gratitude and appreciation to:

Per Fagerholm, my supervisor, for his great visions and for getting me started with this prospective thesis.

Neil Lagali, my supervisor, for all discussions, for revision of the English texts and for all support.

Anatoly Sharipo, my mentor and good friend, for introducing me and teaching me in the field of cell biology, for believing in me and for his vast knowledge

Ainars Leončiks, my colleague, for stimulating discussions, thoughts and guidance.

Žanna Rudevica, my colleague, for helping me in research and skilful assistance in cell culture.

Olena Szymanowsky, my good friend and co-author, for helping me in research, for sharing my good and bad times and for always cheering me up.

Alexander Podskochy, my friend and co-author, for his help and invaluable friendship.

Monica Johnsson, for always kind support with administrative work.

Catharina Traneus-Röckert, for helping me with immunohistochemistry in exceptionally efficient way. 
Colleagues and friends at the Eye Clinic in Linköping and at the Biomedical Study and Research Center in Riga, for all the help and for their knowledge, inspiration and support during my career and working with this thesis.

All my friends, for being very good friends and for everything we had shared.

My loving parents and family, for their love, support and belief in me.

My wonderful children, Jevgenijs and Kira, for endless joy and for being the best gift in my life.

My husband Roman, for his love, for being always on my side, for his absolutely great support and patience. 


\section{References}

Alvarez-Dolado M, Pardal R, Garcia-Verdugo JM, Fike JR, Lee HO, Pfeffer K, Lois C, Morrison SJ, Alvarez-Buylla A. Fusion of bone marrow-derived cells with Purkinje neurons, cardiomyocytes and hepatocytes. Nature 2003; 425(6961):968-973.

Anitua E, Sanchez M, Merayo-Lloves J, De la Fuente M, Muruzabal F, Orive G. Plasma rich in growth factors (PRGF-Endoret) stimulates proliferation and migration of primary keratocytes and conjunctival fibroblasts and inhibits and reverts TGFbeta1-induced myodifferentiation. Invest Ophthalmol Vis Sci 2011; 52:60666073.

Anitua E, Troya M, Orive G. Plasma rich in growth factors promote gingival tissue regeneration by stimulating fibroblast proliferation and migration and by blocking transforming growth factor- $\beta 1$-induced myodifferentiation. J Periodontol 2012a; 83:1028-1037.

Anitua E, Sanchez M, De la Fuente M, Zalduendo MM, Orive G. Plasma rich in growth factors (PRGF-Endoret) stimulates tendon and synovial fibroblasts migration and improves the biological properties of hyaluronic acid. Knee Surg Sports Traumatol Arthrosc 2012b; 20:1657-1665.

Anitua E, Tejero R, Zalduendo MM, Orive G. Plasma rich in growth factors promotes bone tissue regeneration by stimulating proliferation, migration, and autocrine secretion in primary human osteoblasts. J Periodontol 2013a; 84:1180-9110. 
Anitua E, Muruzabal F, Alcalde I, Merayo-Lloves J, Orive G. Plasma rich in growth factors (PRGF-Endoret) stimulates corneal wound healing and reduces haze formation after PRK surgery. Exp Eye Res 2013b; 115:153-161.

Anitua E, Troya M, Orive G. An autologous platelet rich plasma stimulates periodontal ligament regeneration. J Periodontol 2013c; 84:1556-1566.

Azar DT. Corneal angiogenic privilege: angiogenic and antiangiogenic factors in corneal avascularity, vasculogenesis, and wound healing. Trans Am Ophthalmol Soc 2006; 104:264-302.

Azar DT, Chang JH, Han KY. Wound healing after keratorefractive surgery: review of biological and optical considerations. Cornea 2012; 31(Suppl 1):S9-19.

Bahn CF, Falls, HF, Varley GA, Meyer RF, Edelhauser HF, Bourne WM. Classification of corneal endothelial disorders based on neural crest origin. Ophthalmology 1984; 91(6):558-563.

Beales MP, Funderburgh JL, Jester JV, Hassel JR. Proteoglycan synthesis by bovine keratocytes and corneal fibroblasts: maintenance of the keratocyte phenotype in culture. Invest Ophthalmol Vis Sci 1999; 40(8):1658-1663.

Belmonte C, Aracil A, Acosta MC, Luna C, Gallar J. Nerves and sensations from the eye surface. J Ocul Surf 2004; 2(4):248-253.

Bonanno JA. Identity and regulation of ion transport mechanisms in the corneal endothelium. Prog Retin Eye Res 2003; 22(1):69-94. 
Borcherding MS, Blacik LJ, Sittig RA, Bizzell JW, Breen M, Weinstein HG. Proteoglycans and collagen fiber organization in human corneoscleral tissue. Exp Eye Res 1975; 21(1):59-70.

Borrione P, Gianfrancesco AD, Pereira MT, Pigozzi F. Platelet-Rich Plasma in Muscle Healing. Am J Phys Med Rehabil 2010; 89:854-861.

Bourne WM, Nelson LR, Hodge DO. Central corneal endothelial cell changes over a ten-year period. Invest Ophthalmol Vis Sci 1997; 38(3):779-782.

Chakravarti S, Petroll WM, Hassell JR, Jester JV, Lass JH, Paul J, Birk DE. Corneal opacity in lumican-null mice: defects in collagen fibril structure and packing in the posterior stroma. Invest Ophthalmol Vis Sci 2000; 41:3365-3373.

Chaurasia SS, Kaur H, de Medeiros FW, Smith SD, Wilson SE. Dynamics of the expression of intermediate filaments vimentin and desmin during myofibroblast differentiation after corneal injury. Exp Eye Res 2009; 89(2):133-139.

Chen S, Sun M, Meng X, lozzo RV, Kao WW, Birk DE. Pathophysiological mechanisms of autosomal dominant congenital stromal corneal dystrophy: Cterminal-truncated decorin results in abnormal matrix assembly and altered expression of small leucine-rich proteoglycans. Am J Pathol 2011; 179(5):24092419.

Chinnery HR, Humphries T, Clare A, Dixon AE, Howes K, Moran CB, Scott D, Zakrzewski M, Pearlman E, McMenamin PG. Turnover of bone marrow-derived cells in the irradiated mouse cornea. Immunology 2008; 125(4):541-548.

Cintron C, Kublin CL. Regeneration of corneal tissue. Dev Biol 1977; 61(2):346-357. 
Cintron C, Hassinger LC, Kublin CL, Cannon DJ. Biochemical and ultrastructural changes in collagen during corneal wound healing. J Ultrastruct Res 1978; 65(1):1322.

Dastjerdi MH, Soong HK. LASEK (laser subepithelial keratomileusis). Curr Opin Ophthalmol 2002; 13(4):261-263.

Desmouliere A, Chaponnier C, Gabbiani G. Tissue repair, contraction, and the myofibroblast. Wound Repair Regen 2005; 13:7-12.

Di lorio E, Barbaro V, Ruzza A, Ponzin D, Pellegrini G, De Luca M. Isoforms of DeltaNp63 and the migration of ocular limbal cells in human corneal regeneration. Proc Natl Acad Sci USA 2005; 102(27):9523-9528.

Egan CA, Savre-Train I, Shay JW, Wilson SE, Bourne WM. Analysis of telomere lengths in human corneal endothelial cells from donors of different ages. Invest Ophthalmol Vis Res 1998; 39(3):648-653.

Evinger C, Bao JB, Powers AS, Kassem IS, Schicatano EJ, Henriqyez VM, Peshori KR. Dry eye, blinking, and blepharospasm. Mov Disord 2002; 17 Suppl 2:S75-78.

Fagerholm P, Lagali NS, Merrett K, Jackson WB, Munger R, Liu Y, Polarek JW, Söderqvist M, Griffith M. A biosynthetic alternative to human donor issue for inducing corneal regeneration: 24-month follow-up of a phase 1 clinical study. Sci Transl Med 2010; 2(46):46-61.

Ferrari G, Chauhan SK, Ueno H, Nallasamy N, Gandolfi S, Borges L, Dana R. A novel mouse model for neurotrophic keratopathy: trigeminal nerve stereostatic electrolysis through the brain. Invest Ophthalmol Vis Sci 2011; 52(5):2532-2539. 
Ferrari G, Ueno H, Bignami F, Rama P, Dana R. Trigeminal stereostatic electrolysis induces dry eye in mice. Acta Ophthalmol 2013; 91(2):e162-163.

Fini ME. Keratocyte and fibroblast phenotypes in the repairing cornea. Prog Retin Eye Res 1999; 18(4):529-551.

Fini ME, Stramer BM. How the cornea heals: cornea-specific repair mechanisms affecting surgical outcomes. Cornea 2005;24:S2-2S11.

Funderburgh JL, Hevelone ND, Roth MER, Funderburgh ML, Rodrigues MR, Nirankari VS, Conrad GW. Decorin and biglycan of normal and pathologic human corneas. Invest Ophthalmol Vis Sci 1998; 39(10):1957-1964.

Funderburgh JL. Keratan sulfate: structure, biosynthesis, and function. Glycobiology 2000; 10(10):951-958.

Funderburgh JL, Funderburgh ML, Mann MM, Corpuz L, Roth MR. Proteoglycan expression during transforming growth factor beta -induced keratocyte-myofibroblast transdifferentiation. J Biol Chem 2001; 276(47):44173-44178.

Gabison EE, Huet E, Baudouin C, Menashi S. Direct epithelial-stromal interaction in corneal wound healing: Role of EMMPRIN/CD147 in MMPs induction and beyond. Prog Retin Eye Res 2009; 28(1):19-33.

Gallar J, Acosta MC, Moilanen JA, Holopainen JM, Belmonte C, Tervo TM. Recovery of corneal sensitivity to mechanical and chemical stimulation after laser in situ keratomileusis. J Refract Surg 2004; 20:229-235.

Gan L, Fagerholm P, Kim HJ. Effect of leukocytes on corneal cellular proliferation and wound healing. Invest Ophthalmol Vis Sci 1999;40:575-581. 
Germundsson J, Karanis G, Fagerholm P, Lagali N. Age-related thinning of Bowman's layer in the human cornea in vivo. Invest Ophthalmol Vis Sci 2013; 54(9):6143-6149.

Giovanini AF, Gonzaga CC, Zielak JC, Deliberador TM, Kuczera J, Göringher I, de Oliveira Filho MA, Baratto-Filho F, Urban CA. Platelet-rich plasma (PRP) impairs the craniofacial bone repair associated with its elevated TGF-b levels and modulates the co-expression between collagen III and a smooth muscle actin. J Orthop Res 2011; 29:457-463.

Girard MT, Matsubara M, Kublin C, Tessier MJ, Cintron C, Fini ME. Stromal fibroblasts synthesize collagenase and stromelysin during long-term tissue remodeling. J Cell Sci 1993; 104:1001-1011.

Goldman L. Goldman's Cecil Medicine (24th ed.). Philadelphia: Elsevier Saunders; 2012.

Guthoff RF, Wienss H, Hahnel C, Wree A. Epithelial innervation of human cornea: a three-dimensional study using confocal laser scanning fluorescence microscopy. Cornea 2005; 24:608-613.

Hamrah P, Liu Y, Zhang Q, Dana MR. The corneal stroma is endowed with a significant number of resident dendritic cells. Invest Ophthalmol Vis Sci 2003; 44(2):581-589.

Hanna C, O'Brien JE. Cell production and migration in the epithelial layer of the cornea. Arch Ophthalmol.1960;64:536-539. 
Hassell JR, Cintron C, Kublin C, Newsome DA. Proteoglycan changes during restoration of transparency in corneal scars. Arch Biochem Biophys 1983; 222(2):362-369.

Hassell JR, Birk DE. The molecular basis of corneal transparency. Exp Eye Res 2010; 91(3):326-335.

Hayashi K, Sueishi K, Tanaka K, Inomata H. Immunohistochemical evidence of the origin of human corneal endothelial cells and keratocytes. Graefes Arch Clin Exp Ophthalmol 1986; 224(5):452-456.

Hayashi S, Osawa T, Tohyama K. Comparative observations on corneas, with special reference to Bowman's layer and descemet's membrane in mammals and amphibians. Journal of Morphology 2002; 254(3): 247-258.

Hicks C, Crawford G, Chirila T, Wiffen S, Vijayasekaran S, Lou X, Fitton J, Maley M, Clayton A, Dalton P, Platten S, Ziegelaar B, Hong Y, Russo A, Constable I. Development and clinical assessment of an artificial cornea. Prog Retin Eye Res 2000; 19(2):149-170.

Holbach LM, Font RL, Shivitz IA, Jones DB. Bilateral keloid-like myofibroblastic proliferations of the cornea in children. Ophthalmology 1990; 97(9):1188-1193.

Hollingsworth J, Perez-Gomez I, Mutalib HA, Efron N. A population study of the normal cornea using an in vivo, slit-scanning confocal microscope. Optom Vis Sci 2001; 78(19):706-711. 
Ishizaki M, Zhu G, Haseba T, Shafer SS, Kao WW. Expression of collagen I, smooth muscle alpha-actin, and vimentin during the healing of alkali-burned and lacerated corneas. Invest Ophthalmol Vis Sci 1993; 34(12):3320-3328.

Ishizaki M, Wakamatsu K, Matsunami T, Yamanaka N, Saiga T, Shimizu Y, Zhu G, Kao WW. Dynamics of the expression of cytoskeleton components and adherens molecules by fibroblastic cells in alkali-burned and lacerated corneas. Exp Eye Res 1994; 59(5):537-549.

Jester JV, Barry PA, Lind GJ, Petroll WM, Garana R, Cavanagh HD. Corneal keratocytes: in situ and in vitro organization of cytoskeletal contractile proteins. Invest. Ophthalmol. Visual Sci 1994: 35:730-743.

Jester JV, Petroll WM, Barry PA, Cavanagh HD. Expression of alpha-smooth muscle (alpha-SM) actin during corneal stromal wound healing. Invest Ophthalmol Vis Sci 1995; 36(5):809-819.

Jester JV, Huang J, Barry-Lane PA, Kao WW, Petroll WM, Cavanagh HD. Transforming growth factor(beta)-mediated corneal myofibroblast differentiation requires actin and fibronectin assembly. Invest Ophthalmol Vis Sci 1999a; 40(9):1959-1967.

Jester JV, Moller-Pedersen T, Huang J, Sax CM, Kays WT, Cavangh HD, Petroll WM, Piatigorsky J. The cellular basis of corneal transparency: evidence for 'corneal crystallins'. J Cell Sci 1999b; 112(Pt5):613-622.

Jester JV, Petroll WM, Cavanagh HD. Corneal stromal wound healing in refractive surgery: the role of myofibroblasts. Prog Retin Eye Res 1999c; 18(3):311-356. 
Jester JV, Budge A, Fisher S, Huang J. Corneal keratocytes: phenotypic and species differences in abundant protein expression and in vitro light-scattering. Invest Ophthalmol Vis Sci 2005; 46:2369-2378.

Jester JV. Corneal crystallins and the development of cellular transparency. Semin Cell Dev Biol 2008; 19:82-93.

Johnson DH, Bourne WM, Campbell RJ. The ultrastructure of Descemet's membrane. I. Changes with age in normal cornea. Arch Ophthalmol 1982; 100(12):1942-1947.

Johnston MC, Noden DM, Hazelton RD, Coulombre JL, Coulombre AJ. Origins of avian ocular and periocular tissues. Exp Eye Res 1979; 29(1):27-43.

Joseph A, Hossain P, Jham S, Jones RE, Tighe P, Mclntosh RS, Dua HS. Expression of CD34 and L-selectin on human corneal keratocytes. Invest Ophthalmol Vis Sci 2003;44(11):4689-4692.

Joyce NC, Navon SE, Roy S, Zieske JD. Expression of cell cycle-associated proteins in human and rabbit corneal endothelium in situ. Invest Ophthalmol Vis Sci 1996a; 37(8):1566-1575.

Joyce NC, Meklir B, Joyce SJ, Zieske JD. Cell cycle protein expression and proliferative status in human corneal cells. Invest Ophthalmol Vis Sci 1996b; 37(4):645-655.

Kaminska GM, Niederkorn JY. Spontaneous corneal neovascularization in nude mice. Local imbalance between angiogenic and anti-angiogenic factors. Invest Ophthalmol Vis Sci 1993; 34:222-30. 
Karamichos D, Guo XQ, Hutcheon AE, Zieske JD. Human corneal fibrosis: an in vitro model. Invest Ophthalmol Vis Sci 2010; 51(3):1382-1388.

Kenyon KR. Inflammatory mechanisms in corneal ulceration. Trans Am Ophthalmol Soc $1985 ; 83: 610-663$.

Kornmehl EW, Bredvik BK, Kelman CD, Raizman MB, DeVore DP. In vivo evaluation of a collagen allograft derived from rabbit dermis. $J$ Refract Surg 1995; 11(6):502506.

Krachmer H, Manis J, Holland J. Cornea: Fundamentals, Diagnosis and Management. 2nd edn. Elsevier Mosby: Beijing, China, 2005.

Kushida S, Kakudo N, Suzuki K, Kusumoto K. Effects of platelet-rich plasma on proliferation and myofibroblastic differentiation in human dermal fibroblasts. Ann Plast Surg 2013; 71:219-224.

Lagali N, Germundsson J, Fagerholm P. The role of Bowman's layer in corneal regeneration after phototherapeutic keratectomy: a prospective study using in vivo confocal microscopy. Invest Ophthalmol Vis Sci. 2009a; 50(9):4192-4198.

Lagali N, Stenevi U, Claesson M, Fagerholm P, Hanson C, Weijdegård B, Swedish Society of Corneal Surgeons. Survival of donor-derived cells in human corneal transplants. Invest Ophthalmol Vis Sci 2009b; 50(6):2673-2678.

Lagali N, Griffith M, Fagerholm P. In vivo confocal microscopy of the cornea to assess tissue regenerative response after biomaterial implantation in humans. Methods Mol Biol 2013; 1014:211-223. 
Lassen N, Pappa A, Black WJ, Jester JV, Day BJ, Min E, Vasiliou V. Antioxidant function of corneal ALDH3A1 in cultured stromal fibroblasts. Free Radic Biol Med 2006; 41(9):1459-1469.

Lassen N, Black WJ, Estey T, Vasiliou V. The role of corneal crystallins in the cellular defense mechanisms against oxidative stress. Semin Cell Dev Biol2008; 19(2):100-12.

Lee YC, Wang IJ, Hu FR, Kao WW. Immunohistochemical study of subepithelial haze after phototherapeutic keratectomy. J Refract Surg 2001; 17(3):334-341.

Legeais JM, Renard G. A second generation of artificial cornea (Biokpro II). Biomaterials 1998; 24(10):1371-1376.

Li Y, Tan O, Brass R, Weiss JL, Huang D. Corneal epithelial thickness mapping by Fourier/Domain optical coherence tomography in normal and keratoconic eyes. Ophthalmology 2012, 119(12):2425-2433.

Ljubimov AV, Alba SA, Burgeson RE, Ninomiya Y, Sado Y, Sun TT, Nesburn AB, Kenney MC, Maguen E. Extracellular matrix changes in human corneas after radial keratotomy. Exp Eye Res 1998; 67(3):265-272.

Maguen E, Alba SA, Burgeson RE, Butkowski RJ, Michael AF, Kenney MC, Nesburn $\mathrm{AB}$, Ljubimov AV. Alterations of corneal extracellular matrix after multiple refractive procedures: a clinical and immunohistochemical study. Cornea 1997; 16(6):675-682.

Majo F, Rochat A, Nicolas M, Jaoudé GA, Barrandon Y. Oligopotent stem cells are distributed throughout the mammalian ocular surface. Nature 2008; 456(7219):250254. 
Malecaze F, Simorre V, Chollet P, Tack JL, Muraine M, Le Guellec D, Vita N, Arne JL, Darbon JM. Interleukin-6 in tear fluid after photorefractive keratectomy and its effects on keratocytes in culture. Cornea 1997; 16(5):580-587.

Marfurt CF, Murphy CJ, Florczak JL. Morphology and neurochemistry of canine corneal innervation. Invest Ophthalmol Vis Sci 2001; 42:2242-2251.

Marfurt CF. Corneal nerves: Anatomy in Encyclopedia of the Eye, D. A. Dartt, Ed; 2010.

Marfurt CF, Cox J, Deek S, Dvorscak L. Anatomy of the human corneal innervation. Exp Eye Res 2010; 90(4):478-492.

Masur SK, Dewal HS, Dinh TT, Erenburg I, Petridou S. Myofibroblasts differentiate from fibroblasts when plated at low density. Proc Natl Acad Sci USA 1996; 93(9):4219-4223.

Matsubara M, Girard MT, Kublin CL, Cintron C, Fini ME. Differential roles for two gelatinolytic enzymes of the matrix metalloproteinase family in the remodelling cornea. Dev Biol 1991; 147:425-439.

Maurice DM. The location of the fluid pump in the cornea. J Physiol 1972; 221(1):4354.

Michelacci YM. Collagens and proteoglycans of the corneal extracellular matrix. Braz J Med Biol Res 2003; 36(8):1037-1046.

Moore JE, McMullen TC, Campbell IL, Rohan R, Kaji Y, Afshari NA, Usui T, Archer DB, Adamis AP. The inflammatory milieu associated with conjunctivalized cornea 
and its alteration with IL-1 RA gene therapy. Invest Ophthalmol Vis Sci 2002; 43(9):2905-2915 .

Murphy C, Alvarado J, Juster R, Maglio M. Prenatal and postnatal cellularity of the human corneal endothelium. A quantitative histologic study. Invest Ophthalmol Vis Sci 1984; 25(3):312-322.

Müller LJ, Pels L, Vrensen GF. Novel aspects of the ultrastructural organization of human corneal keratocytes. Invest Ophthalmol Vis Sci 1995; 36(13):2557-2567.

Müller LJ, Marfurt CF, Kruse F, Tervo TMT. Corneal nerves: structure, contents and function. Exp Eye Res 2003; 76:521-542.

Oakes JE, Monteiro CA, Cubitt CL, Lausch RN. Induction of interleukin-8 gene expression is associated with herpes simplex virus infection of human corneal keratocytes but not human corneal epithelial cells. J Virol 1993. 67(8):4777-4784.

Ohta T, Kinoshita T, Naito M, Nozaki T, Masutani M, Tsuruo T, Miyajima A. Requirement of the Caspase-3/CPP32 Protease Cascade for Apoptotic Death following Cytokine Deprivation in Hematopoietic Cells. J Biol Chem 1997; 272:23111-23116.

Oyster C. The Human Eye Structure and Function, Sinauer; 1999.

Patel S, McLaren J, Hodge D, Bourne W. Normal human keratocyte density and corneal thickness measurement by using confocal microscopy in vivo. Invest Ophthalmol Vis Sci 2001; 42(2):333-339. 
Pei Y, Reins RY, McDermott AM. Aldehyde dehydrogenase (ALDH) 3A1 expression by the human keratocyte and its repair phenotypes. Exp Eye Res 2006; 83(5):10631073.

Pellegrini JJ, Horn AK, Evinger C. The trigeminally evoked blink reflex. II Mechanisms of paired-stimulus suppression. Exp Brain Res 1995; 107(2):166-180.

Pitts DG. A comparative study of the effects of ultraviolet radiation on the eye. Am J Optom Arch Am Acad Optom 1970; 47(7):535-546.

Pitts DG, Cullen AP, Hacker PD. Ocular effects of ultraviolet radiation from 295 to 365 nm. Invest Ophthalmol Vis Sci 1977; 16(10):932-939.

Podskochy A, Fagerholm P. Repeated UVR exposures cause keratocyte resistance to apoptosis and hyaluronan accumulation in the rabbit cornea. Acta Ophthalmol Scand 2001; 79:603-608.

Podskochy A, Koulikovska M, Fagerholm P, van der Ploeg I. Biglycan gene expression in UVR-exposed rabbit corneas. Acta Ophthalmol Scand 2004; 82(6):707-713.

Robb RM, Kuwabara T. Corneal wound healing. I. The movement of polymorphonuclear leukocytes into corneal wounds. Arch Ophthalmol 1962; 68:636642

Rodriquez-Tarduchy G, Collins M, López-Rivas A. Regulation of apoptosis in interleukin-3-dependent hemopoietic cells by interleukin-3 and calcium ionophores. EMBO J 1990; 9(9):2997-3002. 
Roobol A, Carden MJ. Subunits of the eukariotic cytosolic chaperonin CCT do not always behave as components of a uniform hetero-oligomeric particle. Eur J Cell Biol 1999; 78(1):21-32.

Saika S. Yin and Yang in cytokine regulation of corneal wound healing: Roles of TNF-a. Cornea 2007; 26(9):S70-74.

Senoo T, Joyce NC. Cell cycle kinetics in corneal endothelium from old and young donors. Invest Ophthalmol Vis Sci 2000; 41(3):660-667.

Silver FH, Christiansen DL. Biomaterials science and biocompatibility. New York: Springer, 1999.

Singh V, Agrawal V, Santhiago MR, Wilson SE. Stromal fibroblast-bone marrowderived cell interactions: implications for myofibroblast development in the cornea. Exp Eye Res 2012; 98:1-8.

Sosnová M, Bradi M, Forrester JV. CD34+ corneal stromal cells are bone marrowderived and express hematopoietic stem cell markers. Stem Cells 2005;23(4):507515.

Sotozono C, He J, Matsumoto Y, Kita M, Imanishi J, Kinoshita S. Cytokine expression in the alkali-burned cornea. Curr Eye Res 1997; 16:670-676.

Spadea L, Salvatore S, Vingolo EM. Corneal sensitivity in keratoconus: a review of the literature. The Scientific World Journal 2013.

Stapleton WM, Chaurasia SS, Medeiros FW, Mohan RR, Sinha S, Wilson SE. Topical interleukin-1 receptor antagonist inhibits inflammatory cell infiltration into the cornea. Exp Eye Res 2008;86(5):753-757. 
Sternlicht H, Farr GW, Sternlicht ML, Driscoll JK, Willison K, Yaffe MB. The tcomplex polypeptide 1 complex is a chaperonin for tubulin and actin in vivo. Proc Natl Acad Sci USA 1993; 90(20):9422-9426.

Strissel KJ, Rinehart WB, Fini ME. Regulation of paracrine cytokine balance controlling collagenase synthesis by corneal cells. Invest Ophthalmol Vis Sci 1997; 38:546-552.

Sundarraj N, Fite D, Belak R, Sundarraj S, Rada J, Okamoto S, Hassel J. Proteoglycan distribution during healing of corneal stromal wounds in chick. Exp Eye Res 1998; (67(4):433-442.

Taneri S, Feit R, Azar DT. Safety, efficacy, and stability indices of LASEK correction in moderate myopia and astigmatism. J Cataract Refract Surg 2004; 30(10):21302137.

Terada S, Ota S, Kobayashi M, Kobayashi T, Mifune Y, Takayama K, Witt M, Vadalà G, Oyster N, Otsuka T, Fu FH, Huard J. Use of an antifibrotic agent improves the effect of platelet-rich plasma on muscle healing after injury. J Bone Joint Surg Am 2013; 95:980-988.

Toti P, Tosi GM, Traversi C, Schürfeld K, Cardone C, Caporossi A. CD-34 stromal expression pattern in normal and altered human corneas. Ophthalmology 2002;109(6):1167-1171.

Trinkhaus-Randall V, Wu XY, Tablante R, Tsuk A. Implantation of a synthetic cornea: design, development and biological response. Artif Organs 1997; 21(11):1185-1191. 
Tseng SC, Li DQ, Ma X. Supression of transforming growth factor-beta isoforms, TGF-beta receptor type II, and myofibroblast differentiation in cultured human corneal and limbal fibroblasts by amniotic membrane matrix. J Cell Physiol 1999; 179(3):325-335.

Ueno H, Ferrari G, Hattori T, Saban DR, Katikireddy KR, Chauhan SK, Dana R. Dependence of corneal stem/progenitor cells on ocular surface innervation. Invest Ophthalmol Vis Sci 2012; 53(2):867-872.

Waltman SR, Hart WM, The cornea, in Adler's Physiology of the Eye-Clinical Application, Moses RA and Hart WM, Eds., CV Mosby Coy, St. Louis, Mo, USA, 8th edition, 1987.

Wang DY, Cheng CC, Kao MH, Hsueh YJ, Ma DH, Chen JK. Regulation of limbal keratocyte proliferation and differentiation by TAp63 and DeltaNp63 transcription factors. Invest Ophthalmol Vis Sci 2005; 46(9):3102-3108.

West-Mays JA, Dwivedi DJ. The keratocyte: corneal stromal cell with variable repair phenotypes. Int J Biochem Cell Biol 2006; 38(10):1625-1631.

Wiley L, SundarRaj N, Sun TT, Thoft RA. Regional heterogeneity in human corneal and limbal epithelia: an immunohistochemical evaluation. Invest Ophthalmol Vis Sci 1991; 32(3):594-602.

Wilson SE, He YG, Weng J, Li Q, Mcdowall AW, Vital M, Chwang EL. Epithelial injury induces keratocyte apoptosis: Hypothesized role for the interleukin-1 system in the modulation of corneal tissue organization and wound healing. Exp Eye Res 1996; 62(4):325-327. 
Wilson SE, Kim WJ. Keratocyte apoptosis: implications on corneal wound healing, tissue organization, and disease. Invest Ophthalmol Vis Sci 1998; 39:220-226.

Wilson SE, Hong JW. Bowman's layer structure and function: critical or dispensable to corneal function? A hypothesis. Cornea. 2000;19(4):417-420.

Wilson SE, Mohan RR, Mohan RR, Ambrósio R Jr, Hong J, Lee J. The corneal wound healing response: cytokine-mediated interaction of the epithelium, stroma, and inflammatory cells. Prog Retin Eye Res 2001a; 20(5):625-637.

Wilson SE, Mohan RR, Hong JW, Lee JS, Choi R, Mohan RR. The wound healing response after laser in situ keratomileusis and photorefractive keratectomy: elusive control of biological variability and effect on custom laser vision correction. Arch Ophthalmol 2001b; 119(6):889-896.

Wilson SE, Chaurasia SS, Medeiros FW. Apoptosis in the initiation, modulation and termination of the corneal wound healing response. Exp Eye Res 2007; 85(3):305311.

Wilson SE. Corneal myofibroblast biology and pathobiology: generation, persistence, and transparency. Exp Eye Res 2012; 99:78-88.

Won KA, Schumacher RJ, Farr GW, Horwich AL, Reed SI. Maturation of human cyclin E requires the function of eukariotic chaperonin CCT. Mol Cell Biol 1998; 18(12):7584-7589.

Yoeruek E, Bayyoud T, Maurus C, Hofmann J, Spitzer MS, Bartz-Schmidt KU, Szurman P. Decellularization of porcine corneas and repopulation with human 
corneal cells for tissue-engineered xenografts. Acta Ophthalmol 2012; 90(2):e125131.

Zaniolo k, Carrier P, Guerin SL, Auger FA, Germain L. A tissue-engineered corneal wound healing model for the characterization of reepithelialization. Methods mol biol 2013; 1037:59-78. 
Appendix I-IV 



\section{Papers}

The articles associated with this thesis have been removed for copyright reasons. For more details about these see:

http://urn.kb.se/resolve?urn=urn:nbn:se:liu:diva-114700 